Aus der Klinik für Psychiatrie und Psychotherapie

(Prof. Dr. med. J. Wiltfang)

im Zentrum Psychosoziale Medizin

der Medizinischen Fakultät der Universität Göttingen

\title{
Electronic Media Use and Sleep Disturbance in German Adolescents Aged 11 to 17 Years: \\ A Focus on Insomnia
}

\section{INAUGURAL - DISSERTATION}

Zur Erlangung des Doktorgrades

der Medizinischen Fakultät der

Georg-August-Universität zu Göttingen

vorgelegt von

Anna Karoline Stephens Lange

aus

Boston, Massachussetts, USA

Göttingen 2015 
Dekan:

I. Berichterstatter/in: $\quad$ Priv.-Doz. Dr. med. S. Cohrs

II. Berichterstatter/in:

III. Berichterstatter/in:

Tag der mündlichen Prüfung: 


\section{Outline}

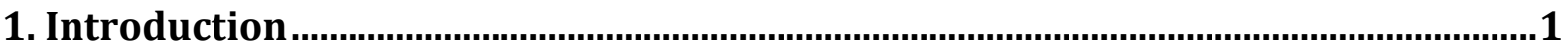

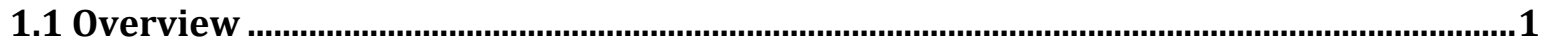

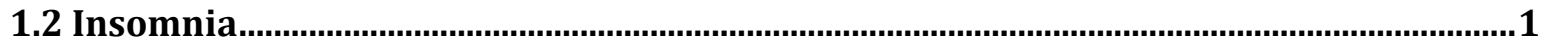

1.2.1 Health Consequences of Insomnia and Comorbidities ....................................... 1

1.2.2 Classification Systems and Diagnostic Criteria ........................................................ 4

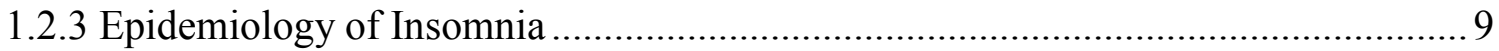

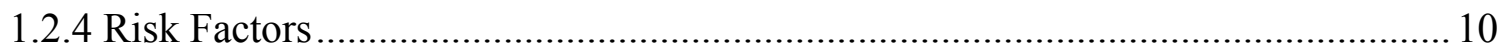

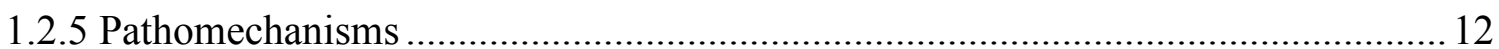

1.2.6 Environmental Factors: Electronic Media Use .................................................... 15

1.2.7 Subjective and Objective Estimates of Insomnia ............................................. 18

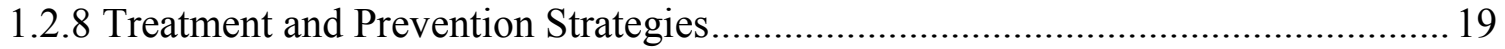

1.2.9 Differential Diagnosis of Delayed Sleep Phase Disorder ..................................... 19

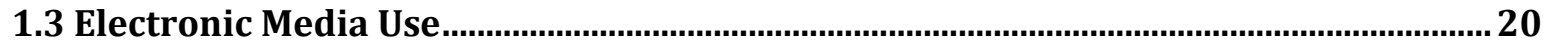

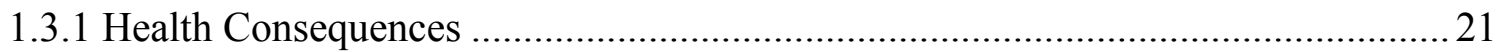

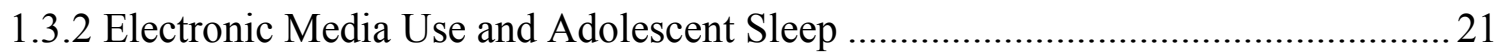

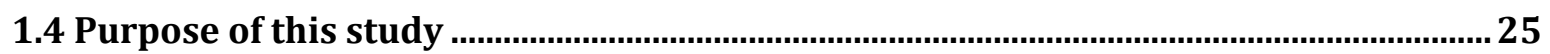

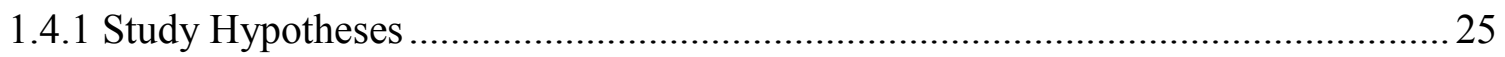

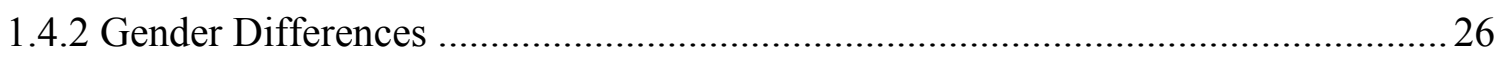

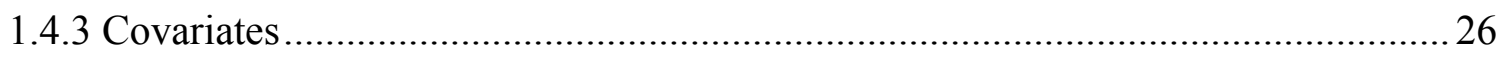

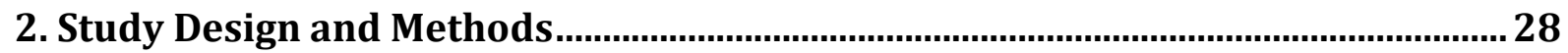

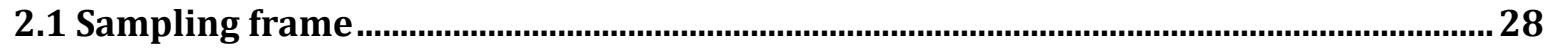

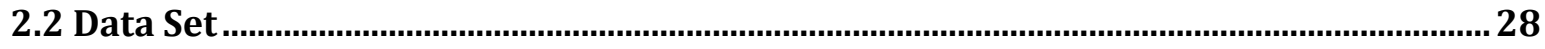

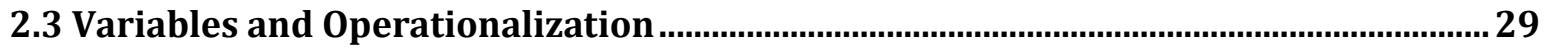

2.3.1 Dependent Variable: Insomnia Complaints ........................................................2 29

2.3.2 Independent Variables: Electronic Media ...............................................................29

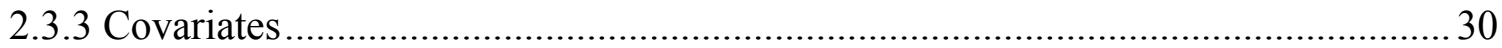

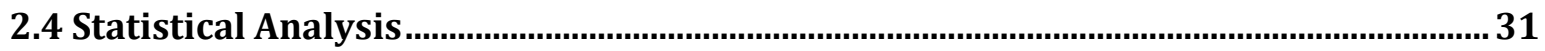

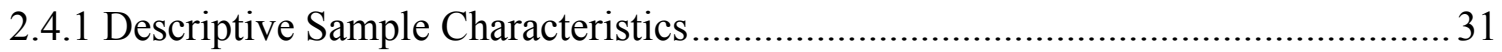

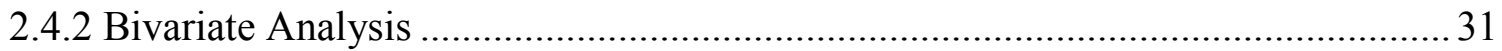

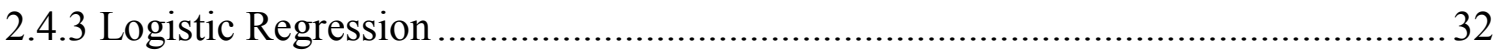


2.4.4 Statistical Analysis Software and Data Set Characteristics .................................. 32

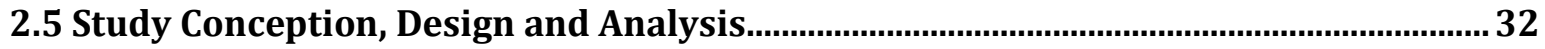

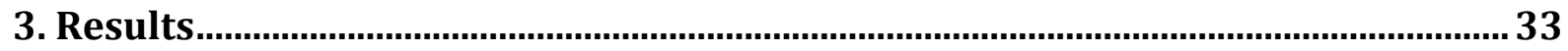

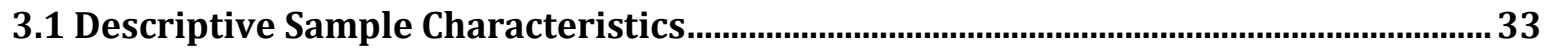

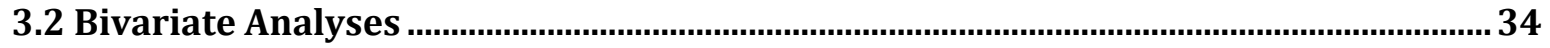

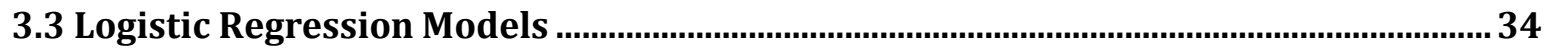

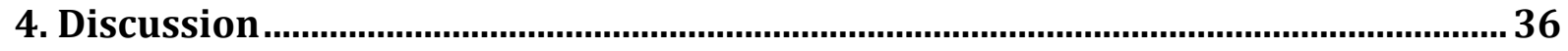

4.1 Significant results

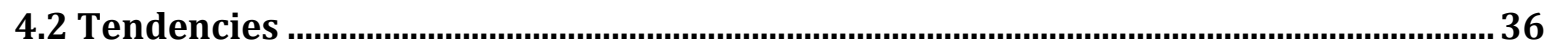

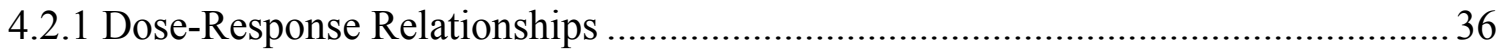

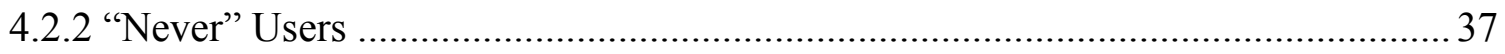

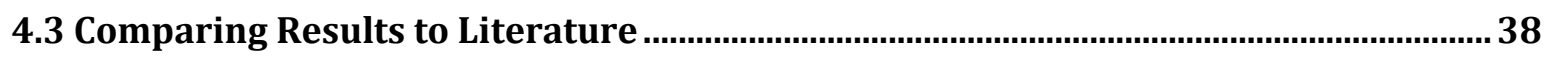

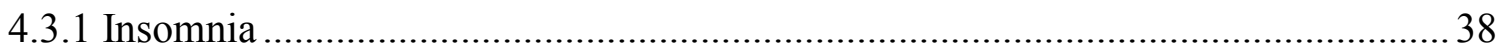

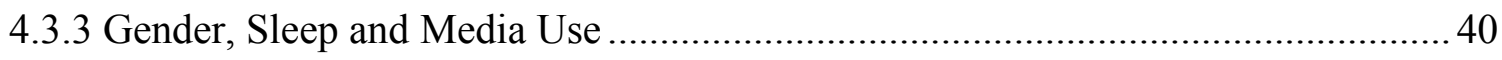

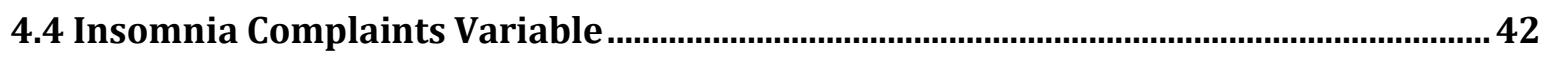

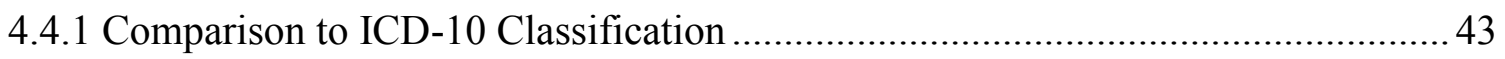

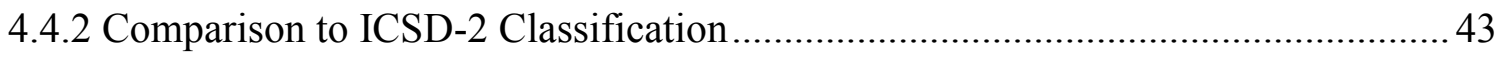

4.4.3 Comparison to DSM-IV and DSM-V Classifications ........................................... 43

4.4.4 Discussion of Insomnia Complaints Variable ...................................................... 44

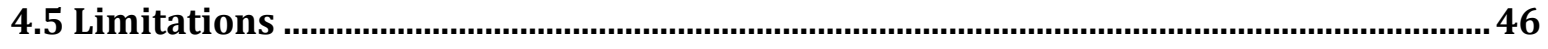

4.5.1 Time of Day and Bedroom Presence of Media ....................................................... 46

4.6.2 Changes in Media Use Patterns Since 2006 …....................................................... 47

4.6.3 Cross-Sectional and Questionnaire-Based Design ................................................ 48

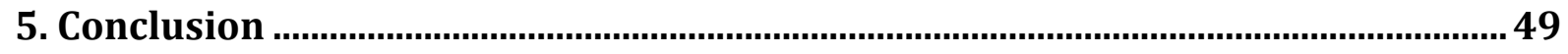

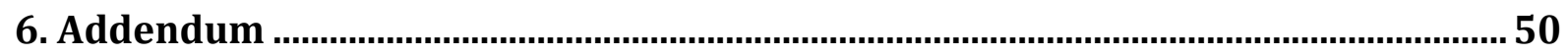

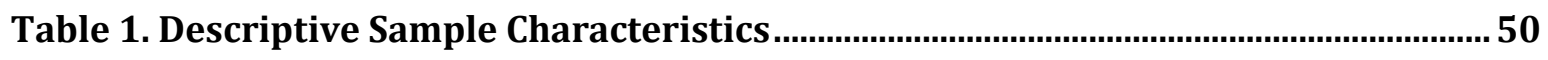

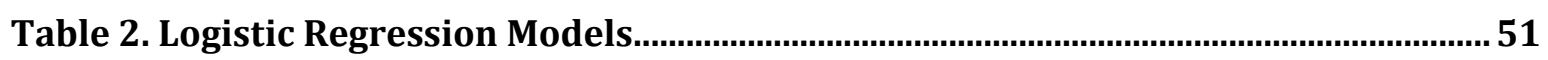

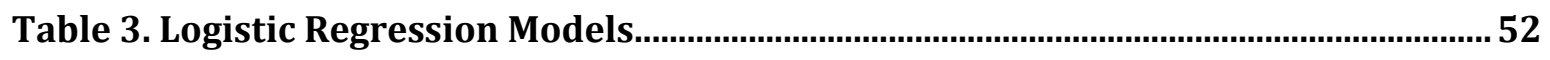

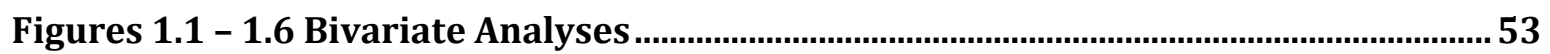

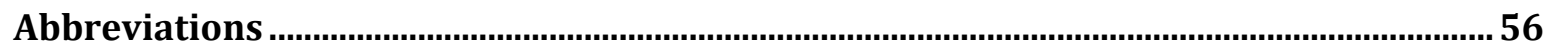

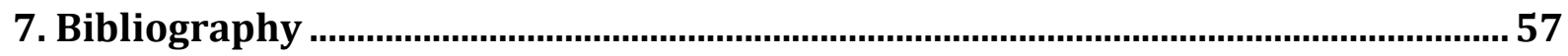

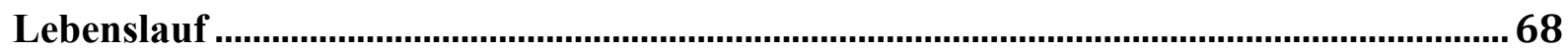




\section{Introduction}

\subsection{Overview}

Electronic media use has gained an increasingly important role in the lives of children and adolescents in most countries around the world and their sleep quality has been shown to be negatively affected by this behavior (Cain and Gradisar 2010). The purpose of this study was to assess associations between the use of different types of electronic media and insomnia complaints (IC) in adolescents. This particular subject is relevant from a clinical as well as a public health perspective as poor sleep has been shown to affect mental and somatic wellbeing (Ancoli-Israel 2006). Furthermore, elucidating the nature of this relationship could provide contributions to the assessment and diagnosis of insomnia in adolescents and have consequences for its prevention and treatment strategies.

In the following chapter, fundamentals of insomnia and current state of research on insomnia in adolescence will be presented. Furthermore, literature on electronic media use in adolescents and the state of research on the relationship between electronic media use and sleep will be reviewed. Finally, rationale and hypotheses for this study will be put forth.

\subsection{Insomnia}

Insomnia is a common disorder affecting approximately $6 \%$ of the population (Ohayon 2002). It has been linked to various detrimental mental and physical health consequences and has a significant negative public health impact.

\subsubsection{Health Consequences of Insomnia and Comorbidities}

\section{Quality of Life, Socioeconomic and Public Health Impacts}

In many cases, insomnia symptoms can develop into a chronic condition (Patten et al. 2000; Roberts et al. 2008b). Chronic insomnia has been shown to have significant associations with various dimensions of perceived quality of life. A large German study from 2001 showed that overall appreciation of quality of life was rated as poor in $22 \%$ of severe insomniacs compared to only $3 \%$ in subjects without sleep complaints (Hajak 2001). Perceived quality of life in insomnia patients has been shown to be comparable to that of patients with chronic conditions like congestive heart failure or depression (Katz and McHorney 2002). Furthermore, the study by Hajak was able to show that the majority of insomniacs suffered 
from other chronic complaints and that consultations with general physicians, medication use, number of medical tests and hospitalizations were greater in severe insomniacs in comparison to subjects without sleep problems. Insomniacs have also been shown to have increased risk for industrial accidents and their work productivity is compromised by higher absenteeism, decreased concentration, and difficulties performing work duties (Leger et al. 2002). A recent study from Canada estimated 10 days of absenteeism and 27.6 days of lost productivity per year for individuals with insomnia syndrome. The annualized population-level estimate of economic burden due to insomnia-related absences was calculated to be 970.6 million Canadian Dollars (Daley et al. 2009).

\section{Psychiatric Comorbidities}

An estimated $40 \%$ of individuals suffering from insomnia have been shown to suffer from a comorbid psychiatric condition, such as anxiety, post-traumatic stress disorder or depression (McCall 2001). In this particular setting, sleep specialists historically agreed that the mental disorder should be recognized as the primary diagnosis and the presence of insomnia symptoms was therefore to be considered as secondary to this condition (Riemann et al. 2014). Yet, in recent years longitudinal studies have shown that this approach needs revision and that the relationships between insomnia symptoms and mental disorders may in fact have to be considered distinctly for each type of mental disorder. For the occurrence of depression, for example, it has been shown that insomnia constitutes an independent risk factor for depression in later life (Baglioni et al. 2011). A review by Taylor et al. (2003) showed that insomnia was a predictor for the occurrence of psychiatric disorders such as depression, anxiety, drug and alcohol abuse or dependence and suicide. Concerning adolescents, a large study from the United States found that $69 \%$ of depression cases were preceded by insomnia. Yet, directionality of risk was reverse for anxiety in this study as it was found that insomnia was preceded by anxiety in $73 \%$ of cases. The authors suggest that the natural course of development of insomnia in relation to depression and anxiety seems to be distinct (Johnson et al. 2006a). Recent research has further substantiated insomnia as an important factor in the multi-factorial etiology of psychiatric disorders (Harvey et al. 2011). Further discussion of the bi-directionality of the relationship between insomnia and psychiatric disorders are outlined in chapter 1.2.2.

\section{Physical Health Comorbidities}

Insomnia is associated with various health problems such as heart disease, hypertension, chronic pain, breathing problems, and increased gastrointestinal, neurologic and urinary 
symptoms, and approximately $75 \%$ of insomnia cases have been found to be associated with another medical or psychiatric condition (Taylor et al. 2007; Lichstein 2006). In a review from 2006, Ancoli-Isreal suggests that it is important to consider the bi-directional nature of relationships between insomnia and chronic illness and that directionality of relationships may differ depending on the nature of the medical condition. For example, sleep problems can be a symptom of a medical condition, such as Cheyne-Stokes respiration in congestive heart failure and arousal and awakenings in gastro-esophageal reflux disease or in certain neurologic disorders. On the other hand, sleep problems can also play a role in the etiology of metabolic conditions such as diabetes mellitus and obesity (Cappuccio et al. 2008; Hayashino et al. 2007). A recent large meta-analysis identified insomnia as a risk factor for developing and/or dying from cardiovascular disease (Sofi et al. 2014). These developments in sleep research precipitated an important shift in this field and in 2005 a decision was made at the National Institutes of Health State Science Conference to replace the term "secondary insomnia" with the more fitting term "comorbid insomnia" (National Institutes of Health (NIH) 2005). Some authors propose bi-directional relationships between insomnia and other health conditions resembling a vicious cycle, in which worsening sleep problems can lead to poorer general health and thereby affect daytime functioning and mood, which in turn can lead to poorer sleep and a downward spiral in the vicious cycle (Harvey and Asarnow 2014). It has been proposed based on research, for example, that effective treatment of sleep problems in patients with chronic pain could in fact promote improvement of perception of pain severity and daily functioning (Drewes et al. 2000).

\section{Adolescent Health Consequences}

Sleep in adolescence has been identified as a particularly important field of research. As overall sleep need becomes greater with puberty, lack of adequate sleep has been shown to have adverse consequences on health and development. During this important developmental stage adolescents have been shown to get less sleep due to phase delay towards later bedtimes and earlier school start times (Carskadon 2011; Crowley et al. 2007). A longitudinal study by Iglowstein et al. in Switzerland showed that at age 6 children get an average of 11 hours of sleep per night, 9.6 hours at age 11 and at age 16 youths get an average of 8.1 hours of sleep. Moreover, young people today get less sleep compared to their counterparts from previous generations (Cain and Gradisar 2010; Iglowstein et al. 2003). In effect, youths in many countries today have decreased total sleep times (TST) and higher incidences of excessive daytime sleepiness (Gradisar et al. 2011). 
Studies on sleep problems in children and adolescents have demonstrated associations with increased risk for injuries and accidents (Lam and Yang 2008), obesity (Chaput et al. 2006; Lumeng et al. 2007; Vioque et al. 2000), subjective somatic health complaints (Roberts et al. 2002; Roberts et al. 2008a), emotional and mood problems (Johnson et al. 2006b; Paavonen et al. 2003), anxiety and major depression (Canals et al. 1997; Johnson et al. 2006a; Patten et al. 2000), behavior and conduct problems (Liu and Zhou 2002; Morrison et al. 1992; Shur-Fen Gau 2006), suicidal behavior (Roane and Taylor 2008; Vignau et al. 1997), smoking, drinking alcohol, and illicit substance use (Johnson and Breslau 2001; Patten et al. 2000; Roane and Taylor 2008; Roberts et al. 2004). In an academic setting, sleep problems were found to be linked to concentration difficulties and decreased declarative, procedural and working memory performance and low self-esteem often resulting in poorer academic performance (Curcio et al. 2006; Dewald et al. 2010; Fredriksen et al. 2004). Few prospective studies showed that poor sleep among children and adolescents preceded depression and interpersonal, psychological, and somatic functioning deficits over time (Roane and Taylor 2008; Roberts et al. 2002). Concerning chronicity of insomnia, a large prospective study was able to show that $45.8 \%$ of adolescents with one or more insomnia symptoms, $34.7 \%$ with insomnia symptoms associated with daytime fatigue and $22.8 \%$ of adolescents diagnosed with DSM-IV primary insomnia developed or maintained chronic insomnia in a follow-up one year later (Roberts et al. 2008b). Another prospective study from the United States found chronicity of sleep problems in 52\% of cases and an increase in frequency of sleep problems compared to baseline in a 4 year follow-up study in $21 \%$ of patients. Notably, female sex and symptoms of depression were both significantly associated with development and persistence of sleep problems in this study (Patten et al. 2000). These consequences for health and development make investigations on the occurrence and etiology of sleep problems in adolescence particularly relevant.

\subsubsection{Classification Systems and Diagnostic Criteria}

The term insomnia fundamentally refers to difficulty sleeping. Yet, insomnia as a clinical diagnosis is subtyped according to frequency of occurrence, duration (acute versus chronic) and etiology. The diagnosis of insomnia can be made according to different classification systems: the International Statistical Classification of Diseases and Related Health Problems (ICD-10) (World Health Organization (WHO) 2010) is used in Germany, but other classification systems such as the International Classification of Sleep Disorders (ICSD-2) (American Academy of Sleep Medicine (AASM) 2005), and the Diagnostic and Statistical 
Manual of Mental Disorders (DSM-IV and DSM-V) (American Psychiatric Association (APA) 2000a and 2013b), are commonly used in other countries. The DSM-V classification is relatively new and was introduced in May 2013. Therefore, both DSM-IV and DSM-V classifications will be outlined in the following. All four classification systems consider the presence of difficulties initiating sleep (DIS) and/or difficulties maintaining sleep (DMS) and/or non-restorative sleep and daytime impairments as cornerstone diagnostic criteria for insomnia. These classification systems each summarize the common defining symptoms of insomnia under different diagnostic terms or categories (ICD-10: nonorganic insomnia; ICSD-2: general criteria for insomnia with reference to subtypes such as psychophysiological insomnia or idiopathic insomnia; DSM-IV: primary insomnia, DSM-V: insomnia disorder). For the sake of better understanding, primary insomnia will from now on be referred to as insomnia that cannot be explained by extrinsic factors, such as impairment of sleep through noise, medications or drugs, or secondary factors such as other sleep disorders or mental or somatic conditions. In the following, common features of these classification systems will be presented and differences will be discussed briefly.

\section{ICD-10}

The ICD-10 differentiates insomnia into nonorganic insomnia and organic insomnia.

Nonorganic insomnia comprises the following features (translated into English from the ICD10 GM (2013)):

1. Complaints of difficulty initiating sleep, difficulty maintaining sleep and/or poor quality of sleep.

2. The sleep problems occur at least 3 times per week over a period of one month.

3. Presence of considerable concern about the sleep problem at night and during the day a disproportionate concern about negative consequences of the sleep problem.

4. The dissatisfactory sleep duration or quality causes significant psychological strain or is disruptive of daily activities.

Furthermore, the ICD-10 notes that insomnia is a common symptom of several mental disorders and medical conditions that cause pain, paresthesias or necessitate medication. The primary diagnosis of the underlying mental disorder or medical condition should be made if insomnia occurs as a symptom of these disorders or conditions and insomnia symptoms do not dominate the clinical picture. 


\section{ICSD-2}

The ICSD-2 is a classification system for sleep specialists and lists general criteria for insomnia as well as specification of eleven different insomnia subtypes among other sleep disorders.

ICSD-2 general criteria for insomnia:

A. A complaint of difficulty initiating sleep, difficulty maintaining sleep, or waking up too early or sleep that is chronically unrestorative or poor in quality. In children, the sleep difficulty is often reported by the caretaker, anxiety may consist of observed bedtime resistance or inability to sleep independently.

B. The above sleep difficulty occurs despite adequate opportunity and circumstances to sleep.

C. At least one of the following forms of daytime impairment related to the nighttime sleep difficulty is reported by the patient:
a. Fatigue
b. Attention, concentration or memory impairment
c. Social or vocational dysfunction or poor school performance
d. Mood disturbance or irritability
e. Daytime sleepiness
f. Motivation, energy, or initiative reduction
g. Proneness for errors or accidents at work or while driving
h. Tension, headaches, or gastrointestinal symptoms in response to sleep loss
i. Concerns or worries about sleep

ICSD-2 diagnostic categories for insomnia subtypes:

- Adjustment Insomnia (acute insomnia)

- Psychophysiological Insomnia (sleep onset insomnia)

- Paradoxical Insomnia

- Idiopathic Insomnia

- Insomnia caused by a mental disorder

- Inadequate sleep hygiene

- Behavioral insomnia of childhood

- Insomnia caused by drug or substance

- Insomnia caused by medical condition 
- Insomnia not caused by substance or known physiologic conditions, unspecified (nonorganic insomnia)

- Physiologic insomnia (organic), unspecified

\section{DSM-IV and DSM-V}

The DSM-IV (Diagnostic and Statistical Manual of Mental Disorders, $4^{\text {th }}$ edition) was published in 1994 and provided the basis for insomnia diagnosis in the United States until the introduction of the DSM-V ( $5^{\text {th }}$ edition) in May of 2013. The DSM-IV distinguishes between primary insomnia and other secondary dyssomnias, such as sleep disorders related to breathing, mental disorders or another medical condition. In the following, the diagnoses of primary insomnia (DSM-IV) and insomnia disorder (DSM-V) will be presented and discussed.

\section{DSM-IV: Primary Insomnia}

A. The predominant complaint is difficulty initiating or maintaining sleep, or nonrestorative sleep, for at least one month;

B. The sleep disturbance (or associated daytime fatigue) causes clinically significant distress or impairment in social, occupational, or other important areas of functioning;

C. The sleep disturbance does not occur exclusively during the course of narcolepsy, breathing-related sleep disorder, circadian rhythm sleep disorder, or a parasomnia;

D. The disturbance does not occur exclusively during the course of another mental disorder (e.g. major depression); and,

E. The disturbance is not due to the direct physiological effects of a substance or a general medical condition.

\section{DSM-V: Insomnia disorder}

A. A predominant complaint of dissatisfaction with sleep quantity or quality, associated with one (or more) of the following symptoms:

a. Difficulty initiating sleep. (In children, this may manifest as difficulty initiating sleep without caregiver intervention.)

b. Difficulty maintaining sleep, characterized by frequent awakenings or problems returning to sleep after awakenings. (In children, this may manifest as difficulty returning to sleep without caregiver intervention.)

c. Early-morning awakening with inability to return to sleep. 
B. The sleep disturbance causes clinically significant distress or impairment in social, occupational, educational, academic, behavioral, or other important areas of functioning.

C. The sleep difficulty occurs at least 3 nights per week.

D. The sleep difficulty is present for at least 3 months.

E. The insomnia is not better explained by and does not occur exclusively during the course of another sleep-wake disorder (e.g. narcolepsy, a breathing-related sleep disorder, a circadian rhythm sleep-wake disorder, a parasomnia).

F. The insomnia is not attributable to the physiological effects of a substance (e.g. a drug of abuse, a medication).

G. Coexisting mental disorders and medical conditions do not adequately explain the predominant complaint of insomnia.

\section{Discussion of Classification Systems in Light of Current Research}

All of the presented diagnostic classification systems have the following criteria for insomnia symptoms in common: DIS and/or DMS and/or non-restorative sleep and daytime impairments or distress resulting from the sleep problem. Specification of subtypes and frequency or duration of insomnia symptoms vary according to classification system. Duration of insomnia is mentioned in the ICD-10, DSM-IV (one month), and DSM-V (3 months), whereas frequency of symptoms is mentioned only in the DSM-V and ICD-10 (3 times per week).

This lack of conformity in classification systems has historical reasons, as the authors of a recent paper titled "Insomnia - State of Science" have put forth. Insomnia symptoms were commonly seen as a secondary feature of an underlying psychiatric or somatic health problem, e.g. major depression, and the prevailing assumption for many years was that insomnia symptoms would subside concurrently with the successful treatment of the underlying condition (Riemann et al. 2014). In light of current studies, this assumption has been revised as it has been shown that insomnia symptoms commonly persist even after successful treatment of major depression. Furthermore, insomnia can in fact precede depression by many years and, therefore, can be seen as an independent risk factor for the development of major depression (Baglioni et al. 2011). Expert opinion in insomnia research now sees insomnia as a prominent factor in the multi-factorial pathogenesis and perpetuation of psychiatric disorders, which is now referred to as a "transdiagnostic" approach to insomnia and mental disorders. The associations between mental disorders and insomnia are considered 
to be bidirectional as insomnia can occur as a symptom, but also constitutes an independent risk factor and can play a role in the perpetuation of the disorder (Harvey et al. 2011). These recent developments in insomnia research gave incentive for restructuring the dichotomous approach to insomnia into primary insomnia and secondary dyssomnias of the DSM-IV. The DSM-V now classifies insomnia disorder as an independent disorder, where somatic and psychiatric disorders can be accounted for as comorbid conditions.

\subsubsection{Epidemiology of Insomnia}

Different classification systems have resulted in different estimates on prevalence rates of insomnia in the general population. Furthermore, insomnia prevalence estimates also depend on the instruments used to ascertain information about sleep and many studies, like this present study, have investigated insomnia symptoms, which do not entirely meet the requirements of insomnia diagnosis. Population based studies from various countries have shown that approximately $33 \%$ of adults suffer from one or more of the common insomnia symptoms (DIS, DMS, early morning awakening and non-restorative sleep) (Ohayon 2002). Yet, the National Institutes of Health State-of-the-Science conference panel statement from 2005 concluded that $10 \%$ of the general population suffers from perceived daytime impairment or distress in addition to common insomnia symptoms. Finally, few studies were designed to adhere to stringent diagnostic criteria, such as DSM-IV, and these are summarized and discussed in an important review by Ohayon on insomnia epidemiology (Ohayon 2002). DSM-IV insomnia diagnosis, which includes primary insomnia, insomnia disorder related to another mental disorder, substance-induced insomnia type sleep disorder, and insomnia type sleep disorder due to a medical condition, was found to range from 4.4 $6.4 \%$ in the general population worldwide. Among insomnia diagnoses, primary insomnia was most common with prevalence rates from $2 \%$ to $4 \%$. Interestingly, Ohayon notes that about one third of subjects with insomnia symptoms had a comorbid mental condition effectively ruling out the diagnosis of DSM-IV defined primary insomnia. Furthermore, prevalence of insomnia related to another mental disorder ranged from $1 \%$ to $3 \%$ and ranked second only to primary insomnia among DSM-IV insomnia diagnoses. These prevalences of insomnia can now be viewed in a different light after the introduction of DSM-V classification, since the diagnosis of insomnia disorder can now be made even in the presence of a comorbid condition such as major depression. Yet, the DSM-V guideline has stricter quantitative measures for insomnia diagnosis, which will possibly have an effect on insomnia prevalence rates in studies among the general population subsequent to its introduction. The 
new criteria include a minimum frequency of 3 nights per week and a minimal duration of symptoms of 3 months.

In adolescents, insomnia has been subject to investigation in many countries over the past decades. Prevalences vary depending on the sleep parameters investigated. A highly cited and large study by Ohayon et al. from 2000 found a prevalence rate for DSM-IV defined insomnia of $4 \%$ in European adolescents aged 15 to 18 years. Interestingly, of the subjects diagnosed with insomnia about half were diagnosed with DSM-IV defined primary insomnia, $27 \%$ had insomnia related to a comorbid psychiatric disorder, $12 \%$ to substance use and $7 \%$ related to another medical condition. The authors note that primary insomnia was the only genderrelated insomnia diagnosis with $3.4 \%$ prevalence for females and $1.2 \%$ for males. Another important study conducted by Johnson et al. in the United States using the DSM-IV criteria showed a lifetime prevalence of $10.7 \%$ in adolescents aged 13 to 16 years. Of subjects diagnosed with insomnia, 52\% suffered from a comorbid psychiatric disorder. Furthermore, this study found that females had a 2.75 -fold increased risk for insomnia with onset of menses (Johnson et al. 2006b). A large telephone interview study conducted in Texas by Roberts et al. found DSM-IV primary insomnia prevalence of 5.3\%. Prevalence of one or more insomnia symptoms was $13.9 \%$ and $5.5 \%$ for one or more insomnia symptoms associated with daytime sleepiness, which were controlled for psychiatric disorders and substance use (Roberts et al. 2008b). A recent large study from 2013 comparing insomnia prevalences in adolescents in Norway according to DSM-IV and DSM-V criteria showed much higher insomnia prevalence rates of $23.8 \%$ (DSM-IV) and 18.5\% (DSM-V) and 13.6\% using quantitative criteria including duration of symptoms for at least 6 months and sleep onset latency (SOL) and/or wake after sleep onset of at least 30 minutes (Hysing et al. 2013). Many other studies have investigated insomnia symptoms and prevalence rates range depending on the number and importance of symptoms. Studies investigating DIS, DMS and non-restorative sleep have shown prevalences ranging from $10.8 \%$ to $34 \%$ (Liu et al. 2000a; Ohayon et al. 2000; Roberts et al. 2004).

\subsubsection{Risk Factors}

In his review from 2002, Ohayon presents literature on insomnia epidemiology and identifies important risk factors and associated factors for insomnia. In the following, relevant risk factors for adolescent insomnia are presented and discussed. 
In adults, the overwhelming majority of studies found increasing prevalence estimates of insomnia with older age (Ohayon 2002). In adolescents, occurrence of insomnia and insomnia symptoms also increase with age, as many studies have shown (Gau et al. 2004; Kaneita et al. 2006; Liu and Zhou 2002; Roberts et al. 2006). Median onset of insomnia has been demonstrated to occur at age 11 and females tend to develop insomnia earlier than males by about 2 years (Johnson et al. 2006b). For late adolescence and early adulthood, no difference in DSM-IV defined insomnia prevalences was found in European adolescents aged 15 to 18 years compared to young adults aged 19 to 24 years (Ohayon et al. 2000). Prevalence rates remain stable in middle adulthood and then rise once again with seniority (Ohayon 2002).

\section{Gender}

In the general population females are more likely to have insomnia symptoms and sleep problems than males (Ohayon 2002). For adolescents in particular, many studies have shown higher prevalences of sleep problems (Chung and Cheung 2008; Dorofaeff and Denny 2006; Lumeng et al. 2007) and insomnia symptoms for females (Alexandru et al. 2006; Knutson and Lauderdale 2009; Roane and Taylor 2008). A gender difference for DSM-IV defined insomnia was found in the study previously mentioned by Johnson et al. with a prevalence of $12.4 \%$ for female and $8.9 \%$ for male adolescents. Of note, onset of menses in girls coincided with an increase in risk for insomnia by 2.75 and females in post-menses status were 2.5 times more likely to have insomnia. No significant difference in risk was found before onset of menses for females compared to their male counterparts (Johnson et al. 2006b). DSM-IV defined primary insomnia diagnosis was also found to be gender related in a large study on 15 to 18 year-old adolescents and young adults by Ohayon et al. with prevalence rates of $3.4 \%$ for females and $1.2 \%$ for males (Ohayon et al. 2000). Some studies show higher prevalence rates, such as the study from Norway comparing DSM-IV and DSM-V diagnoses, which showed 29.5\% DSM-IV defined insomnia for females and 17.1\% for males, and 18.5\% DSM$\mathrm{V}$ defined insomnia for females and $12.5 \%$ for males (Hysing et al. 2013).

\section{Socioeconomic Status}

Review of many studies found associations between individual income and education levels with insomnia in the general population. Lower income and educational levels were associated with higher insomnia prevalences. Yet, Ohayon remarks in his review that many studies lack multivariate analyses in order to substantiate these factors as independent risk factors (Ohayon 2002). In adolescents, studies have shown that lower parental education 
levels and lower family income were associated with DSM-IV defined insomnia (Johnson et al. 2006b; Roberts et al. 2006). However, one study from China showed parental occupation and education levels to be unrelated to insomnia symptoms (Liu et al. 2000a). Concerning sleep duration, several studies on children and adolescents were able to show that reduced TST was related to lower socioeconomic status (SES) (Dorofaeff and Denny 2006; McLaughlin Crabtree et al. 2005). Yet, short sleep duration is not considered a diagnostic criterion for insomnia disorder.

\section{Medical Condition}

As mentioned in Section 1.2.1, directionality of risk between somatic health problems and insomnia must be viewed with caution as evidence is still scarce in this field. Furthermore, directionality of risk is assumed to shift depending on the nature of the health problem (Ancoli-Israel 2006). For further discussion please refer to section 1.2.1.

\section{Drugs and Medication}

Smoking and alcohol use have been shown to be related to adolescent sleep problems including insomnia (Johnson and Breslau 2001; Ohayon and Zulley 2001; Patten et al. 2000; Roane and Taylor 2008). The use, abuse and/or withdrawal of other psychoactive substances such as caffeine, hypnotics, anxiolytics, sedatives, cocaine, amphetamines and opiods can also result in development of self-induced acute or chronic insomnia (Ohayon 2002).

\subsubsection{Pathomechanisms}

In this chapter, theories on pathomechanisms for insomnia will be presented and discussed. Furthermore, hypotheses on media use and its potential role in the etiology of insomnia will be assessed in relation to the existing hypotheses for pathomechanisms. Main references used for review of up-to-date concepts of pathomechanisms and treatment strategies can be found in a chapter on insomnia by Harvey and Asarnow in the Wiley Handbook of Cognitive and Behavioral Therapy (2014) and a review on insomnia by Riemann et al. (2014).

\section{Three-Factor Model (Spielman)}

An established heuristic model by Spielman, Caruso and Glovinsky (1987b) distinguishes predisposing (e.g. character traits), precipitating (e.g. psychosocial stressors) and perpetuating factors (e.g. poor coping strategies) relevant to the evolution of chronic insomnia. This model is also often referred to as the Three-P Model. Predisposing factors can be present in certain individuals and are considered trait characteristics of increased vulnerability for sleep disturbance in response to environmental and psychological stressors. This trait vulnerability 
has been described in depth in most current research as "sleep reactivity" and has been shown to have a substantial genetic component (Drake et al. 2011). Precipitating factors may be of heterogeneous nature and can cause situational insomnia. Situational insomnia is defined as poor sleep in relation to stressors arising from circumstance, which can occur for example in form of new sleep environment, situational life stress, circadian shifts or CNS stimulants (Bonnet and Arand 2003). Perpetuating factors can be poor sleep hygiene, use of alcohol as a sleep aid and increased time spent in bed, which are common pre-sleep coping strategies seen in insomniacs. Therapeutic intervention strategies have been developed according to this model in form of sleep restriction therapy, which is considered an effective treatment strategy for insomnia patients (Morin et al. 2006; Spielman et al. 1987a).

\section{Behavioral Model}

Bootzin (1973) developed a behavioristic approach to insomnia etiology and postulates that insomnia can occur when an individual ceases to associate his or her bed with restorative sleep. This model is based on the principles of conditioning and stimulus control, which have found implementation in intervention strategies with high efficacy in treatment of insomnia (Morin et al. 2006).

\section{Cognitive Models}

Harvey developed a cognitive model of insomnia, in which cognitive processes occurring during the day and at night contribute to maintenance of insomnia. Key cognitive processes in this cascade are a) worry and rumination, b) selective attention and monitoring, c) misperception of sleep and daytime deficits, d) dysfunctional beliefs about sleep, and e) counterproductive safety behaviors that serve to maintain beliefs about sleep (Harvey 2002). Other authors have also conceptualized cognitive models for insomnia (Espie et al. 2006; Morin et al. 1993). Concepts from these models have found implementation in and have become integral parts of cognitive-behavioral therapy treatment strategies with proven shortand long-term efficacy (Riemann et al. 2014).

\section{Hyperarousal Models}

Although behavioristic and cognitive models have found recognition in successful treatment strategies, perceptions of insomnia as a primarily behavioral or emotional problem are considered historical. Hyperarousal concepts of insomnia have been substantiated by in depth research in the past years. Increased levels of arousal parameters on autonomous, neuroendocrine, neuroimmunological, electrophysiological and neuroimaging levels during 
the day and at night have been found to play a key role in pathophysiology of insomnia (Bonnet and Arand 2010; Riemann et al. 2010). Insomniacs have been shown to have changes in autonomic functioning and over-activation in neuroendocrine stress systems in response to and interrelating with sleep deprivation (Bonnet and Arand 1998; Haynes et al. 1981; Meerlo et al. 2008; Rodenbeck et al. 2002). Meerlo et al. postulate in a review on this subject that an over-activation of stress response systems can precipitate an increase in susceptibility to certain stimuli, which would normally not be perceived and processed as pertinent stressors by the brain. This concept is also known as stress responsivity (Meerlo et al. 2008). In recent years sleep researchers have developed the concept of sleep reactivity, which is a similar concept to that of stress responsivity, but entails increased susceptibility in certain individuals to react to external or internal stressors with sleep disturbance and hyperarousal (Drake et al. 2004). For example, Fernández-Mendoza et al. showed that pre-sleep cognitive and somatic arousal, arousability, emotion-oriented coping and rumination where associated with higher FIRST scores (Ford Insomnia Response to Stress Test), a parameter reflecting exaggerated sleep disturbance in response to challenges (Fernandez-Mendoza et al. 2010).

Perlis et al. conceptualized a neurocognitive model that extends behavioral perspectives and concepts of predisposing, precipitating and perpetuating factors by encompassing continued arousal as a perpetuating factor. The perspective of going to bed and an environment suggesting sleep become important stimuli for arousal. Arousal is conceptualized in this model as increased somatic, cognitive and cortical activation (Perlis et al. 1997; Riemann et al. 2010). Somatic arousal refers to increased levels of metabolic activity and physiological parameters. There is evidence showing that increased maximal oxygen consumption, brain metabolism, cardiac measures, body temperature, and hormone measures (increased levels of cortisol, adrenocorticotropic hormone (ACTH), norepinephrine, interleukin-6, and decreased melatonin secretion at night) are present in insomnia patients (Bonnet and Arand 2010). Cognitive arousal refers to mental constructs like worry or rumination about sleep and heightened attention on sleep (Espie et al. 2006), but this concept cannot be distinctly differentiated from cortical arousal. Additionally, insomniac patients exhibit electroencephalographic and Multiple Sleep Latency Test (MSLT) correlates reflecting increased levels of sensory and information processing during sleep initiation. Enhanced sensory processing is thought to render the individual susceptible to perturbation by environmental stimuli (e.g. sound) during sleep and sleep onset, and this heightened information processing may distort individual distinction between sleep and wakefulness. 
Furthermore, abnormally enhanced information processing and long-term memory formation may explain the tendency in insomniacs to experience polysomnography-defined sleep as wakefulness (Riemann et al. 2010).

\subsubsection{Environmental Factors: Electronic Media Use}

As mentioned in chapter 1.2.1, TST in adolescents has decreased over the past decades. Cain and Gradisar (2010) discuss in an important review on media use and sleep that the prevailing assumption in the past was that adolescents simply develop a biologically decreased "sleep need" during pubertal development. Yet, they mention a later important study in this field that was unable to show a difference in intrinsic sleep need when comparing youths at different pubertal stages who were given the opportunity to sleep 10 hours per night (Carskadon et al. 1980). The authors propose that environmental and psychosocial factors such as rules at home and increased use of electronic media have a considerable influence on the amount of sleep obtained by adolescents. In this review, Cain and Gradisar go on to elegantly summarize existing hypotheses on mechanisms by which media use can have an effect on sleep. In short, presence of an electronic media device in the bedroom can lead to increased daytime and prebedtime media use. Bedroom presence and the amount of time spent per day with electronic media devices could furthermore be associated with age of the child, household parental rules and/or SES of the family. The three mechanisms by which sleep could be influenced by electronic media use that they put forth are: 1) increased use at night directly displaces sleep resulting in decreased sleep times, i.e. displacement hypothesis, 2) increased cognitive, emotional and/or physiological arousal is caused by media use and disrupts sleep, and 3) bright light emitted from screens or electromagnetic transmission from a mobile phone delays circadian rhythm (electromagnetic transmission was added by Gradisar et al. in 2013).

The first mechanism, displacement of sleep through evening and nighttime media use, is simply explained by later bedtimes and early wake-up times of adolescents during the week due to school commitments leading to decreased sleep times. This mechanism could also explain daytime sleepiness, but shorter sleep time would not be considered a sleep disorder per se. Yet, later average bedtimes could cause delayed sleep phase, as has been suggested in a previous study on adults (Brunborg et al. 2011), and thereby provoke insomnia symptoms to a certain extent, but only if the sleep delayed individual tried to reverse this delay by attempting sleep initiation earlier than usual. The third hypothesis refers to effects of bright light exposure on circadian rhythm. Evening exposure to bright light can increase SOL (Dijk et al. 1991) and some authors have brought forth evidence that light emissions from electronic 
devices (i.e. LED-backlit computer screens) used prior to sleep may have an effect on circadian rhythm by means of changes in nocturnal melatonin levels and core body temperature (Higuchi et al. 2003; Kubota et al. 2002). However, an adverse effect of lightemitting screens on SOL could not be substantiated in adolescents (Heath et al. 2014) or young adults (Higuchi et al. 2005). Concerning electromagnetic transmission, there is some evidence supporting that nighttime mobile phone emissions could affect melatonin onset times as well (Wood et al. 2006).

The second mechanism is particularly interesting considering existing hypotheses on and evidence for pathomechanisms of insomnia discussed earlier in this chapter. Considering the Three-P Model by Spielman and the neurocognitive concept by Perlis et al., media use could represent a precipitating and/or a perpetuating factor in the pathogenesis of insomnia. The content the adolescent is exposed to during pre-sleep media use, i.e. a violent computer game or stressful social interaction via social media, could evoke arousal responses through cognitive or emotional stressors (precipitating factors) thereby causing situational sleep disturbance. Foley et al. propose in their study on pre-sleep activities in children that prior evidence shows that "thriller" or action-oriented electronic games can stimulate wakefulness through heightened cognitive processes, such as fear and excitement (Foley et al. 2013). Other authors have also referred to violent media content with fear-provoking, and, generally, rousing themes possibly relating to sleep disturbance (Eggermont and Van den Bulck 2006). Yet, the evidence they cite does not support the causative nature of this sleep disrupting mechanism.

This hypothesis of arousal has been investigated, although with inconclusive results, by Ivarsson et al. in their study on 22 boys in Sweden, where results pointed towards a stronger autonomic activation after violent gaming compared to the non-violent condition. Nonetheless subjects in the violent gaming group did not have sleep disturbance the night following gaming conditions (Ivarsson et al. 2009b). Another study by Ivarsson et al. showed that saliva cortisol levels were unchanged after violent gaming and, furthermore, levels were in fact stable to lower the morning after violent gaming conditions (Ivarsson et al. 2009a). In an experimental study by King et al., objective sleep efficiency, TST and subjective SOL were decreased after prolonged violent gaming, although heart rates before and under gaming conditions were comparable to a normal resting condition and did not differ significantly from pre-sleep heart rates (King et al. 2012). Dworak et al. showed that playing computer games 2 to 3 hours before bedtime prolonged SOL and reduced stage 2 sleep and slow wave sleep for 
males (Dworak et al. 2007). These results suggest that emotionally stressful stimuli conveyed through electronic media may in fact lead to sleep disruption, although possibly not through mechanism of autonomic arousal or increased neuroendocrine stress response. Similarly, Kok et al. suggested in their study on adults that emotional stress responses may be evoked by certain stressors without provocation of adreno-cortical responses (Kok et al. 1995).

A recent study on 738 adolescents aged 11 to 13 by Arora et al. was able to show that the use of electronic media was associated with sleep onset problems and with difficulty shutting off the mind when attempting to fall asleep (Arora et al. 2014). Difficulties in cognitively shutting off in association with media use has to date only been investigated in one prior study in which pre-sleep video gaming was shown to be associated with increased parameters for cognitive alertness, but not with physiological arousal (heart rate) during the use of the media device. This study found that pre-sleep video gaming was weakly associated with increased SOL and reduced subjective sleepiness, but no changes in sleep architecture were seen (Weaver et al. 2010). Arora et al. propose that visual content exposure and/or cognitive processes (decision-making, problem-solving, memory) occurring during engagement with electronic media devices could explain difficulty shutting off before sleep and sleep onset problems. For another recently published study by Gradisar et al. this hypothesis of heightened arousal through the use of stimulating media devices provided the basis for investigation. It was hypothesized that the use of stimulating media devices in the hour before bedtime would be associated with sleep problems and the study results confirmed this hypothesis: the use of more interactive media devices (computers/laptops, mobile phones, video game consoles) was associated with higher likelihood of having difficulties falling asleep and unrefreshing sleep, whereas the use of more passive media devices (i.e., television, listening to music) was not (Gradisar et al. 2013).

When considering electronic media as a perpetuating factor of insomnia, it is important to consider the evidence on heightened stress responsivity in sleep disturbed individuals (Meerlo et al. 2008). This evidence makes the assumption plausible that arousing stimuli conveyed through electronic media can be perceived and processed as stressors by the brain of a sleep deprived individual and, therefore, perpetuate the heightened activity of stress response systems ultimately leading to a chronic insomniac state. In conclusion, there is some evidence that media use and certain media content can result in heightened arousal and precipitation of insomnia symptoms, such as sleep onset problems, but the evidence is insufficient to make a direct connection to pathomechanisms of insomnia. 


\subsubsection{Subjective and Objective Estimates of Insomnia}

\section{Subjective Estimates}

As can be reviewed in the ICD-10, ICSD-2, and DSM-IV and DSM-V classification systems, insomnia is assessed according to subjective measures. Gold standard in assessment of most sleep disorders is the structured patient interview. The interview should include information about the nature of the sleep complaint (DIS, DMS, early morning awakening, and/or nonrestorative sleep) and about the onset, duration, course over time, frequency, severity, weekday and weekend variability, and precipitating or alleviating factors. It is important that the interviewer considers comorbid psychiatric and medical problems. Other factors concerning sleep hygiene are also of importance such as activities engaged in after retiring to bed, time of lights out, time out of bed in the morning and psychoactive substance use. A helpful tool in the patient interview can also be a "focused lens" approach on a typical recent night of poor sleep, which can be helpful in assessing various emotional, behavioral and cognitive processes contributing to the experienced sleep problems. Another cornerstone in insomnia diagnosis is the assessment of sleep with a sleep diary, which the patient completes each morning for a period of one to two weeks.

Validated questionnaires can also be used to index the presence and severity of sleep disturbance and are of particular interest in sleep research. Commonly used sleep indexes are the Pittsburgh Sleep Quality Index (PSQI) (Buysse et al. 1989) and the Insomnia Severity Index (Bastien et al. 2001). Ohayon and colleagues have developed a computerized tool, the Sleep-EVAL system, which guides a structured interview on insomnia symptoms and this system has been applied in several large studies assessing insomnia prevalences (Ohayon et al. 1999).

\section{Objective Estimates}

Polysomnography (PSG) is considered the gold standard in assessment of sleep architecture and is used to evaluate sleep stages by recording electrical brain activity via electroencephalogram, eye movements via electroocculogram and muscle tone via electromyogram. Hereby, sleep specialists can evaluate changes in sleep architecture and possible awakenings, as occur for example in sleep disordered breathing. Although PSG offers the most detailed information about sleep, this measure is not recommended for routine assessment unless the patient is considered to have comorbid sleep disorders such as periodic limb movements or sleep disordered breathing, or if treatment was not effective. Another 
objective means of sleep evaluation is actigraphy, which is a method by which physical motion is recorded via a small wrist worn device in order to assess resting activity patterns at night. The recorded data can be used to evaluate periods of wakefulness and sleep during the night.

\subsubsection{Treatment and Prevention Strategies}

Treatment and prevention of insomnia is a large field in sleep research and sleep literature and this chapter aims merely to briefly introduce commonly implemented and validated treatment strategies and new approaches to prevention, as results of this study may have consequences in these fields. For further review of treatment strategies please refer to a review by Riemann and Perlis from 2009.

The two main pillars of sleep treatment are cognitive behavioral therapy (CBT), which includes behavioral, cognitive and psychoeducative aspects, and pharmacological treatment with benzodiazepine receptor agonists (BZRAs) and other sleep promoting agents. Methods used in CBT are stimulus control, relaxation techniques, sleep hygiene instructions, sleep restriction and cognitive techniques such as cognitive restructuring and paradoxical intention. CBT has been shown to be effective in the short-term and also to have sustainable gains in long-term follow up (Morin et al. 2006). BZRAs on the other hand have been shown to have short-term effectiveness, yet only a very limited number of studies have shown evidence for durable effectiveness in the long term (Riemann and Perlis 2009). CBT is unfortunately not always available to individuals in need of treatment, since CBT is commonly offered in specialized sleep centers. Interestingly, a promising approach to filling this gap in accessibility to specialized sleep treatment is being developed and tested in some countries: the introduction of internet-based prevention and treatment programs. The intervention methods used in CBT could hereby become readily available to a much greater number of individuals with sleep problems and would represent cost and time effective treatment and prevention options for the general public (Riemann et al. 2014).

\subsubsection{Differential Diagnosis of Delayed Sleep Phase Disorder}

Delayed sleep phase disorder (DSPD) is a common sleep disorder that affects up to $16 \%$ of adolescents and young adults according to a recent review by Gradisar and Crowley (2013). Its cornerstone symptom is daytime sleepiness, which is why DSPD should be considered a differential diagnosis when assessing sleep problems with daytime sleepiness in young adults. According to ICSD-2 and DSM-V classifications, DSPD is recognized as normal sleep that is 
significantly delayed in timing with respect to the desired sleep onset and rising times. The experienced sleep onset delay is usually significant with sleep onset occurring between 1 a.m. and 6 a.m.. This delayed sleep pattern is considered a disorder when the experienced sleep deficit significantly impacts individual functioning, which is particularly relevant for young individuals with school commitments. DSPD has been shown to be associated with daytime sleepiness at school and poor school performance, but also with comorbid depression and anxiety (Bartlett et al. 2013; Gradisar and Crowley 2013). Bartlett et al. cite evidence in their review showing that about $10 \%$ of individuals diagnosed with chronic insomnia in sleep clinics actually had DSPD. Since sleep phase is delayed, individuals with DPSD continually experience short sleep duration and feel permanently tired and exhausted. This may falsely lead to the diagnosis of insomnia, or psychophysiological insomnia, which is commonly referred to as sleep-onset insomnia, in which the chief complaint in DIS (Bartlett et al. 2013).

Several factors have been associated with DPSD, such as psychoactive substance use (i.e. tobacco, alcohol, caffeine), anxiety and depression symptoms and poor sleep hygiene such as bedroom presence and bedtime use of electronic media. Furthermore, it has been discussed that DPSD symptomatology can overlap with sleep-onset insomnia, since most adolescents seeking help for DPSD report heightened cognitive activity (racing and/or intrusive thoughts) in bed when trying to fall asleep (Gradisar and Crowley 2013).

\subsection{Electronic Media Use}

In a 2006 poll by the National Sleep Foundation in the United States, 97\% of adolescents reported having at least one electronic media device in their bedroom and the presence of more than 4 devices was associated with significantly less sleep on school nights and weekends (National Sleep Foundation 2006). Another study on technology use (television, computer, phone/cellular, MP3 player) in the United States showed that adolescents engage in 4 electronic media activities after $9 \mathrm{pm}$ on average, which corresponded to 5.3 hours (Calamaro et al. 2009). In Germany, the KiGGS (German Health Interview and Examination Survey for Children and Adolescents) found that male adolescents aged 11 to 17 years spent an average of 3.8 hours and female adolescents an average of 2.7 hours per day in front of a screen (television, computer/internet, video games). 95.7\% of adolescents watched television every day, $92.5 \%$ listened to music, $76.0 \%$ of adolescents used the computer or internet, $33.5 \%$ played video games and $62.0 \%$ used a mobile phone on a daily basis (Lampert et al. 2007). The KiGGS data provided the basis for this study. 


\subsubsection{Health Consequences}

Electronic media have been studied extensively during the past decades and it has become clear that the use of media has associations to negative impacts on mental and somatic health of children and adolescents. Electronic media use has been associated with aggressive or violent behavior (Johnson et al. 2002; Singer et al. 1998), obesity (Vioque et al. 2000), poor body concept and self-image, higher levels of "trauma symptoms", such as anxiety, depression, post-traumatic stress (Singer et al. 1998), substance use (Sargent et al. 2006), early sexual activity (Brown et al. 2006) and poor overall perceived health (Choi et al. 2009; Punamaki et al. 2007; Soderqvist et al. 2008). It has also been shown that adolescent sleep is negatively impacted by media use (Cain and Gradisar 2010), and this will be discussed in detail in the following chapter.

\subsubsection{Electronic Media Use and Adolescent Sleep}

\section{Television}

Television viewing has been shown to be associated with sleep disturbance in children and adolescents and this appears a worldwide phenomenon relying on data from Europe, North America, Australia and Asia (Cain and Gradisar 2010). After 9 p.m. in the evenings, 82\% of adolescents have been found to report watching television and 34\% report watching DVDs or videos (Calamaro et al. 2009). Television watching has been associated with changes in sleep times, specifically with later bedtimes (Adam et al. 2007; Knutson and Lauderdale 2009; Thorleifsdottir et al. 2002; Tynjala et al. 1993; Van den Bulck 2004), reduced time in bed (Eggermont and Van den Bulck 2006; Van den Bulck 2004) and reduced TST (Adam et al. 2007; Ortega et al. 2010; Shochat et al. 2010; Thorleifsdottir et al. 2002). Insomnia symptoms such as delayed sleep onset or DIS (Alexandru et al. 2006; Johnson et al. 2004; Shochat et al. 2010), DMS (Johnson et al. 2004) and daytime sleepiness (Eggermont and Van den Bulck 2006; Gaina et al. 2007; Saarenpää-Heikkilä et al. 2000; Van den Bulck 2004) have also been shown to be associated with watching television. One experimental study showed reduced sleep efficiency (percentage of sleep time in relation to time spent in bed) in 11 male adolescents following exposure to a subjectively exciting film 2 to 3 hours before bedtime. Yet, there was no effect seen on parameters such as SOL and waking time after sleep onset (Dworak et al. 2007). Arora et al. (2014) showed in their study from the United Kingdom that frequent bedtime television viewing was associated with decreased TST by about 20 minutes, but not with prolonged SOL. However, some studies found no significant correlation between 
television viewing during the day and sleep duration in children (Nixon et al. 2008) or adequate sleep in adolescents (Chen et al. 2006).

When considering bedroom presence of electronic media, youths who had a television set in their bedroom went to bed significantly later on weekdays and got up significantly later on weekends (Van den Bulck 2004). Watching television as a sleep aid specifically was investigated by Eggermont and Van den Bulck, an evening activity that $36.7 \%$ Belgian adolescents engaged in. They were able to show that watching television as a sleep aid was associated with later bedtimes, sleeping less during the week and higher levels of tiredness (Eggermont and Van den Bulck 2006).

A longitudinal study from the United States on 759 subjects found that adolescents who watched 3 hours or more of television per day at age 14 were at significantly higher risk for development of sleep problems in early adulthood, even when controlling for age, sex, previous sleep problems, psychiatric disorders, parental education level and annual income, parental neglect and parental psychiatric symptoms. Furthermore, adolescents who chose to reduce television viewing time to less than one hour per day were shown to have a significantly decreased risk for the occurrence of sleep problems at an early adulthood followup (Johnson et al. 2004). Cain and Gradisar (2010) summarize their review on television stating that the most consistent findings on sleep disturbance in association to television use are decreased TST, delayed bedtimes and prolonged SOL.

\section{Electronic Games and Computer}

For the sake of better comprehension of literature review, both playing video games and playing computer games are reviewed in combination in this part of the chapter. Some studies have investigated the more broad description of this media type and content as "digital" or "electronic" games and these are not pointed out specifically. Furthermore, most studies that included data collection on the use of computers specifically investigated playing games or using the internet. The few studies that investigated computer use other than for these purposes (i.e. for emailing or studying) are mentioned in the latter.

Prolonged playing of video games or computer games has been associated with later bedtimes and reduced TST (King et al. 2012; Punamaki et al. 2007; Van den Bulck 2004) and reduced overall sleep quality (Mesquita and Reimao 2007). Furthermore, this activity has also been shown to be associated with insomnia symptoms such as increased SOL (Alexandru et al. 2006; Higuchi et al. 2005; King et al. 2012; Weaver et al. 2010) and daytime sleepiness 
(Gaina et al. 2007; Van den Bulck 2004). Calamaro et al. found that $25 \%$ of American adolescents played computer games after 9 p.m. (Calamaro et al. 2009). Using computer games as a sleep aid was investigated by Eggermont and Van den Bulck and 28.2\% of male and $14.7 \%$ of female Belgian adolescents reported engaging in this activity. They were able to show that playing computer games as a sleep aid was associated with later bedtimes, sleeping less during the week and higher levels of tiredness (Eggermont and Van den Bulck 2006).

Mesquita and Reimao demonstrated in a smaller study on Spanish adolescents that nightly engagement with the more broad term "computer use" was associated with reduced overall sleep quality (PSQI), daytime sleepiness and lower probability of being a "good sleeper" (Mesquita and Reimao 2007). Knutson and Lauderdale also investigated computer use and found that every one hour increase during the day of this activity delayed bedtime by about 15 minutes (Knutson and Lauderdale 2009). A Finnish study showed that computer usage (playing digital games, internet surfing and computer use for emailing and writing) was associated with poor perceived health through deteriorated sleeping habits waking-time tiredness for males, but not for females (Punamaki et al. 2007). The recent study by Arora et al. (2014) investigated computer or laptop use for studying and this was found to be associated with decreased weekday sleep time.

\section{Internet}

Internet use and sleep problems in adolescents has been well studied over the past years. Van den Bulck conducted a large study, in which he measured time spent per day with the internet and associated sleep disturbance. He was able to show that adolescents who spent more time during the day using the internet had later bedtimes, spent less overall time in bed and had higher levels of reported tiredness during the day (Van den Bulck 2004). In a study conducted by Cheung and Wong in Hong Kong, significant associations between internet addiction and insomnia (PSQI) were found in 10 to 14 year-olds and addicts scored significantly poorer in all PSQI components except in TST compared to non-addicted counterparts (Cheung and Wong 2011). Another large study conducted in South Korea demonstrated associations between internet addiction and decreased TST, insomnia symptoms and excessive daytime sleepiness in high school students. (Choi et al. 2009) Furthermore, problematic internet use was significantly associated with subjective insomnia and short sleep duration in 12 to 18 year-old Taiwanese students in another large study conducted by Yen et al. (Yen et al. 2008). 


\section{Mobile Phones}

Söderqvist et al. analyzed associations between mobile phone use and health symptoms in adolescents and found tiredness and concentration difficulties during the day and insufficient sleep to be associated with increased use (Soderqvist et al. 2008). Harada et al. found that Japanese adolescents using their mobile phones on a daily basis were more likely to be evening-typed, meaning that they had higher activity levels in the evenings, and to have later wake-up times and shorter sleep duration (Harada et al. 2002). However, another Japanese study did not find mobile phone use to be associated with SOL (Gaina et al. 2005). The Finnish study by Punamaki et al. (2007) showed that mobile phone use was associated with shorter sleep duration, poor perceived health through deteriorated sleeping habits and wakingtime tiredness for females, but not for males. Yet, Yen et al. from Taiwan found no significant association between short sleep or subjective insomnia with mobile phone use in their study including 8004 adolescents (Yen et al. 2008).

According to Calamaro et al., 34\% of American adolescents used their phones for text messaging and 44\% for talking on the phone after 9 p.m. in the year 2007 (Calamaro et al. 2009). Mobile phones were a common reason for being interrupted during sleep in Belgian adolescents and the use at night was related to increased tiredness during the day concurrently (Van den Bulck 2003) and one year later (Van den Bulck 2007).

\section{Music}

Considering media device preferences, many studies have shown that listening to music, along with watching television, is the most common activity involving electronic media that adolescents engage in on a regular basis (Strasburger et al. 2010). Yet, associations with sleep problems are not well investigated to date. In their review on electronic media use and sleep in adolescence, Cain and Gradisar (2010) identified music as a possible contributor to sleep problems and pointed out the need for more research in this field. Eggermont and Van den Bulck found the use of music as a sleep aid to be related to less TST on weekdays, later bedtimes on weekdays and higher levels of tiredness (Eggermont and Van den Bulck 2006). Furthermore, listening to music was found to be one of the most common late night activities in Saudi Arabian adolescents contributing to reduced sleep time (Qidwai et al. 2010). Arora et al. (2014) showed that frequent listening to music in the bedroom was significantly associated with reduced weekday sleep time, prolonged SOL, difficulty falling to sleep, and nightmares. 
An experimental study on 12 adult subjects investigated the effect of music as an instrument for staying awake. Non-sleep-deprived subjects had increased sleep onset latencies in the Multiple Sleep Latency Test (MSLT) and higher physiological arousal signs (heart rate) when listening to music compared to testing conditions in a quiet surrounding, although this effect could not be observed in sleep deprived subjects (Bonnet and Arand 2000).

\section{Multitasking and Screen Time}

Several studies have also emphasized associations between screen media or multitasking with various types of electronic media and sleep problems. Calamaro et al. found a high multitasking index after 9 PM (which includes television, computer, cellular phone and MP3 use) to be associated with less sleep, falling asleep during school and difficulties falling asleep on weeknights (Calamaro et al. 2009). A large study by Olds et al. in Australia observed that screen time (television, computer, video games, cinema) was inversely related with TST in 103910 to 13 year-old adolescents (Olds et al. 2006). Intensive information and communication technology habits (computer, internet, mobile phones) were furthermore shown to be associated with poor perceived health, which was mediated by deteriorated sleeping habits and waking-time tiredness in 12 to 18 year-old Finnish adolescents (Punamaki et al. 2007). Increased electronic media exposure, which included television time and internet time, predicted later bedtimes, longer sleep latency during the weekdays and later wake-up times on the weekends in Hebrew-speaking adolescents (Shochat et al. 2010). The recent study by Gradisar et al. (2013) with data collected in the United States found that the amount of media used in the bedroom in the hour before bedtime was significantly associated with DIS and that the use of an increased number of devices during this time was associated with more severe DIS. When focusing on interactive compared to passive devices in detail they found that passive devices (television, listening to music) did not significantly contribute to sleep disturbance, whereas interactive media use (video gaming, mobile phone use, computer/laptop use) was associated with DIS and unrefreshing sleep.

\subsection{Purpose of this study}

\subsubsection{Study Hypotheses}

The purpose of this study was to investigate associations of insomnia complaints (IC) with several types of electronic media in adolescents aged 11 to 17 years. Watching television, playing video games, using the computer/internet as well as total screen time, using a mobile phone and listening to music were considered as independent variables. Past research and 
hypotheses on the sleep disrupting effects of media use discussed in chapters 1.2.6 and 1.3.2 provided the incentive and rationale for this study. It was assumed that possible associations between IC and media use can be explained by a direct effect the use of electronic media devices could have on sleep. A causal relationship was therefore considered to underlie possible associations. It was hypothesized that increased time spent per day with the use of electronic media devices would be associated with IC in adolescents.

\subsubsection{Gender Differences}

Various studies on the use of electronic media and sleep problems in adolescence have been conducted over the past years displaying different associations with sleep problems depending on the type of media investigated. Most studies presented in chapter 1.3.2 took gender into account in multivariate analysis, such as the longitudinal study on television use by Johnson et al. (2004) or the study by Arora et al. (2014), where several types of media were investigated and gender, among other covariates, was controlled for in the final adjusted model. Yet, few studies have actually conducted separate analyses for males and females in order to show possibly different associations between sleep disturbance and different types of media use. Studies have shown that males and females have different preferences for certain types of media (Ohannessian 2009) and that insomnia prevalences also differ by gender depending on developmental stage (Johnson et al. 2006b). Therefore, conduction of separate investigations for males and females with regard to different types of media use and their associations to IC was considered important to take into account and, moreover, an expansion of existing sleep research.

\subsubsection{Covariates}

The broad range of health related topics covered in the KiGGS data set, which is introduced in chapter 2.2, offered the possibility to control for known risk factors for insomnia in the analysis. In order to account for the effect of these risk factors on possible associations between media use and IC, odds ratios (OR) were calculated in logistic regression analyses before (unadjusted model) and after controlling for covariates (adjusted model). The intention hereby was to achieve effect sizes in the adjusted logistic regression model that were as specific as possible for measuring the hypothesized associations by excluding the possibility that known risk factors were confounding the measured associations. The measured effect sizes in the adjusted model therefore were expected to be as uniquely attributable as possible to the independent variables (i.e. time spent with different types of media) by excluding effects caused by known confounding covariates. A number of covariates were considered, 
such as age, socioeconomic status (SES), anxiety/depression, health status, symptoms of pain, body mass index, pubertal status and psychoactive substance use (i.e. caffeine, alcohol, smoking). However, some of these covariates were not shown to have confounding effects on the associations between media use and IC and, therefore, were omitted in the final adjusted model in order to maintain statistical power. Included covariates are presented in chapter 2.3.3. 


\section{Study Design and Methods}

\subsection{Sampling frame}

The German Health Interview and Examination Survey for Children and Adolescents (KiGGS) was commissioned by the German Ministry of Health and conducted by the Robert Koch-Institute from May 2003 until May 2006. The aim of this study was to ascertain nationally representative data on the health status of German children and adolescents aged 0 to 17 years. KiGGS is a unique study, since widespread representative data had never before been collected to this extent in Germany. Of the 17,641 children and adolescents enrolled in this survey 8985 were males and 8656 were females. Subjects were randomly and representatively selected from an inventory of German communities and the parents or legal guardian were contacted by mail. Of 28,299 contacted subjects a total of $17,641(66.6 \%$ response rate) participated in the survey. The full scope of the KiGGS comprised a questionnaire for the parent or legal guardian, a self-report questionnaire for subjects 11 years and older, a physical examination and interview by a study physician, and laboratory testing. The KiGGS study was approved by the Charite Universitätsmedizin ethics committee and the German Federal Office for The Protection of the Data and was supervised by a scientific advisory board. For more information on objectives, design and measures of the KIGGS study see (Kurth et al. 2008).

The focus of this study on sleep relied on the questionnaires administered to the adolescents and their parent or guardian. These questionnaires included a number of components aiming to gather information on somatic and mental health, living conditions and health-relevant behavior of children and adolescents in Germany. Questions concerning media use and sleep characteristics were also included in the questionnaires and provided the basis for this investigation on IC and electronic media use.

\subsection{Data Set}

In December 2008 the Robert Koch-Institute designated the KiGGS basic data set as a public use file and it was opened to the public by the center for research data "Health Monitoring" of the Robert Koch Institute. Requirement for use of this data for research purposes was a founded professional interest and the exclusion of commercial interest in or commercial use of this data. 


\subsection{Variables and Operationalization}

\subsubsection{Dependent Variable: Insomnia Complaints}

The insomnia complaints (IC) variable comprises several items from the KiGGS children's questionnaire on sleep problems and daytime functioning. However, a specific instrument for collecting data on sleep problems was not included in the KiGGS. The subjects were asked if they experience sleep problems and, if they affirmed, were summoned to specify whether they had (1) difficulties initiating sleep (DIS) or (2) difficulties maintaining sleep (DMS). Subjects were considered positive for IC if they reported DIS or DMS in combination with feeling „tired and lacking energy“ over the past week at least „often“ or „always“ on a five-point scale.

\section{Questions from the KiGGS Children's Questionnaire (in German)}

41 Leidest du unter Schlafschwierigkeiten?

Ja

(

Ich kann schlecht einschlafen ........... K065a

Ich kann schlecht durchschlafen .... K065b
K065

Nein

2

$\bigcirc 1$

$\bigcirc 1$

25 Zuerst möchten wir etwas über deinen Körper wissen:

$\begin{array}{llclll}\text { In der letzten Woche ... } & \text { Nie } & \text { Selten } & \text { Manchmal } & \text { Oft } & \text { Immer } \\ 3 & \ldots . . . \text { war ich müde und erschöpft } & & & \end{array}$

\subsubsection{Independent Variables: Electronic Media}

To assess the average amount of time spent each day by each adolescent with television viewing, using the computer/internet, playing video games, using a mobile phone, or listening to music the subject was asked to specify "the average amount of time spent per day" with each type of media on a 5-point scale: (1) not at all, (2) about 30 minutes, (3) about 1 to 2 hours, (4) about 3 to 4 hours, (5) more than 4 hours. These time use categories were then pooled for stronger reliability of results: (1) Never, (2) $0,5-2 \mathrm{~h} / \mathrm{d}$, and (3) $\geq 3 \mathrm{~h} / \mathrm{d}$.

In order to approach the average amount per day spent in front of a screen the variable ,total screen time“" was created by generating an index for the time spent using screen based media (i.e. television, computer/internet and video games). The index was created according to the 
following scheme: about 30 minutes $=0.5$, about 1 to 2 hours $=1.5$, about 3 to 4 hours $=3.5$, and 4 hours or $=5$. The indices for each media type were then added and re-categorized into 3 categories: (1) $0-<4 \mathrm{~h} / \mathrm{d}$, (2) $4->8 \mathrm{~h} / \mathrm{d}$ and (3) $\geq 8 \mathrm{~h} / \mathrm{d}$.

\section{Question from the KiGGS Children's Questionnaire (in German)}

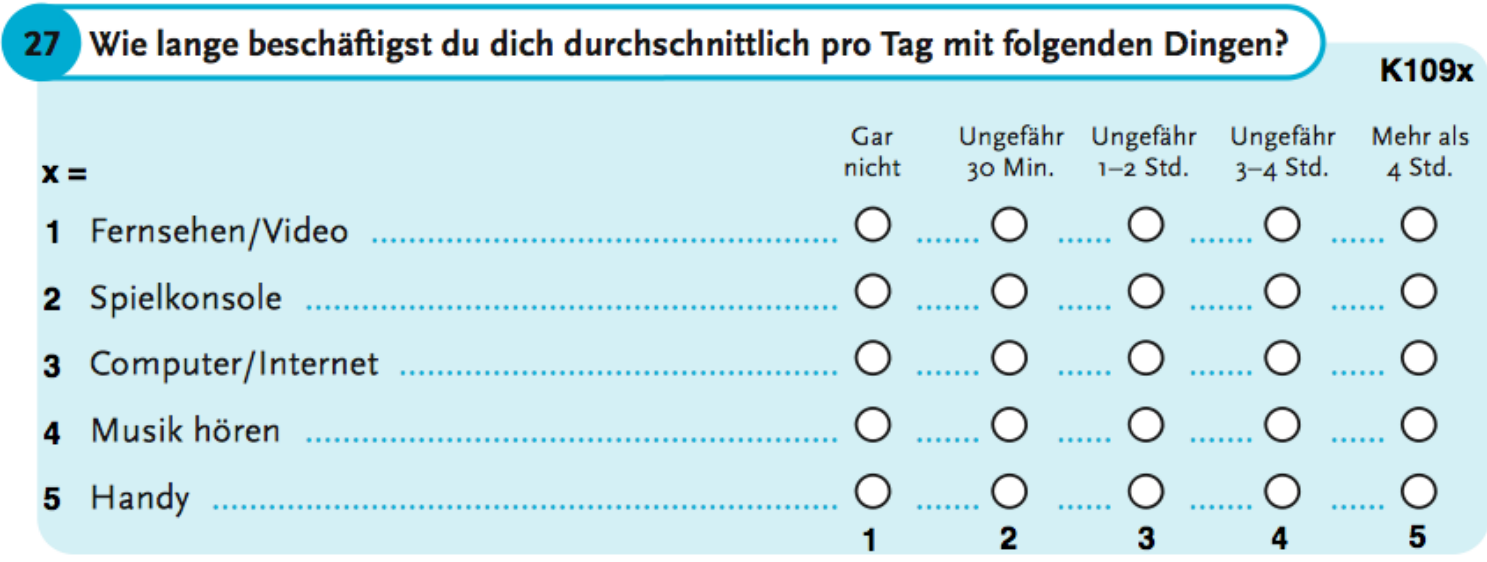

\subsubsection{Covariates}

The following variables were considered as covariates as suggested by pertinent current literature mentioned in chapter 1.2.4. These covariates were included in the adjusted logistic regression analysis in order to account for possible confounding by these known risk factors for insomnia.

\section{Gender}

Gender was taken into account by performing separate bivariate and logistic regression analyses for male and female adolescents.

\section{Age}

Age was considered in full years in this study. Adolescents from 11 to 17 years of age were included. Pubertal status was considered as a possible confounding factor, as discussed in chapter 1.2.4, but associations were found to be covered by adjusting for age. Pubertal status was therefore not included as a covariate in the final logistic regression analysis.

\section{Socioeconomic Status}

Socioeconomic Status (SES) of the family was assessed by the Winkler Index (Winkler and Stolzenberg 1999), which includes information on educational levels of the mother and father, monthly family income and vocational status of both parents. The Winkler Index was then categorized into low, middle and high SES. 


\section{Anxiety and Depression}

The Strengths and Difficulties Questionnaire (SDQ) was included in the KiGGS in order to screen for adolescents with emotional and/or behavioral problems (Goodman 1997). In particular, the emotional problems subscale of the SDQ was used in this study, which was included in the questionnaire for parents and represents a validated instrument for identifying individuals with symptoms of anxiety and depression. Symptoms of anxiety and depression were scored and then classified as „normal“, „borderline“, or ,abnormal“ according to English normative data.

\section{Medical Condition}

In order to identify and include adolescents with physical health problems and symptoms of chronic pain, the variable "medical condition" was created. The Children with Special Health Care Needs (CSHCN)- Screener was included in this variable in order to identify adolescents who currently experienced one or more of five common health problems (McPherson et al. 1998). In addition, having experienced pain several times per week or daily during the past three months was also considered a medical condition. Adolescents met the criteria for "medical condition", if they fulfilled the CSHCN criteria and/or suffered from pain several times per week or daily over the past 3 months.

\subsection{Statistical Analysis}

\subsubsection{Descriptive Sample Characteristics}

In step one of analysis, descriptive characteristics of the sample were assessed. The prevalences of the categories of the dependent variable (IC), the independent variables (watching television, using the computer/internet, playing video games, using a mobile phone and listening to music) and covariates were determined in separate approaches for males and females.

\subsubsection{Bivariate Analysis}

In a second step, bivariate analyses were conducted to determine the relationship between IC (dependent variable) and time use categories (never, $0.5-2 \mathrm{~h} / \mathrm{d}, \geq 3 \mathrm{~h} / \mathrm{d}$ ) with the investigated types of electronic media (independent variables). Prevalences for IC were determined in percentage values. Separate analyses were performed for males and females. 


\subsubsection{Logistic Regression}

In a third step, logistic regression analyses were performed in two separate models in order to describe effect sizes (i.e. odds ratios (ORs)) for the association between media use (dependent variables) and IC (independent variable). In the unadjusted model, ORs were determined for IC in association with the time use categories for each type of electronic media. In the adjusted model, ORs for IC were assessed adjusting for age, SES, anxiety/depression and medical condition. Separate analyses were performed for males and females.

\subsubsection{Statistical Analysis Software and Data Set Characteristics}

All analyses were carried out using SAS version 9.3 (SAS Institute Inc., Cary, United States). To account for the survey structure of the sample the SAS survey procedures were employed. The analyses are based on weighted data, which represent the population structure of the Federal Republic of Germany with respect to age, gender, place of residence, and place of origin (reference population data from 31.12.2004). The number of subjects referred to in this manuscript are therefore weighted and rounded and can differ from the numbers of subjects from other KiGGS publications.

\subsection{Study Conception, Design and Analysis}

The conception of this study was initiated by a task force on adolescent sleep under supervision of Priv.-Doz. Dr med. Stefan Cohrs in cooperation with the Robert KochInstitute. The conception, design and interpretation of the results of this study were done by the author in collaboration with the task force. Statistical analysis was conducted by Robert Schlack, Robert Koch-Institute Berlin, in close collaboration with the author. The author contributed to the statistical analysis by presenting a founded analytical concept for the study hypotheses and by proposing operationalization for variables based on state of the art theories and literature in sleep medicine. Data extraction and interpretation of results were undertaken by the author in collaboration with the task force on adolescent sleep. 


\section{Results}

\subsection{Descriptive Sample Characteristics}

Insomnia Complaints, Gender, Age, Socioeconomic Status, Anxiety/Depression, Medical Condition

The results of the first step of analysis are displayed in table 1 (see Addendum, Table 1.). A total of 7533 adolescents aged 11 to 17 years were included in this study. The sample consisted of 3862 males and 3671 females and the mean age was 14.2 years (standard error: 0.01). IC were found to be present in $4.2 \%$ of male and in $7.4 \%$ of female subjects. All ages from 11 to 17 years were equally represented. About $47 \%$ of adolescents fell into the middle category for SES and about 25 to $27 \%$ into the high and low categories for SES. Abnormal scores for anxiety and depression symptoms were seen in $8.4 \%$ of males and $11.0 \%$ of females, borderline scores in $6.7 \%$ and $7.8 \%$ and normal scores in $84.9 \%$ of males and $81.1 \%$ of females. Furthermore, $25.6 \%$ of male subjects and $30.9 \%$ of female subjects fulfilled the criteria for being classified as having a medical condition.

\section{Electronic Media Use}

Table 1 (Addendum, Table 1) shows descriptive characteristics of the time use categories for television, computer/internet, video games, total screen time, mobile phones and music for males and females. Over $95 \%$ of adolescents watched at least 30 minutes of television every day and about one quarter of them watched television for $\geq 3 \mathrm{~h} / \mathrm{d}$. No remarkable gender differences were appreciated for television use. The computer/internet was used by more males and over $80 \%$ of them used this medium every day compared to about $70 \%$ of females. About three times as many males used the computer/internet for $\geq 3 \mathrm{~h} / \mathrm{d}$ compared to females (16.9\% versus $6.4 \%$ ). Over $80 \%$ of females reported never playing video games, but about $50 \%$ of males played video games every day. When regarding total screen time, the majority of males and females reported having spent less than 4 hours per day in front of a screen. Yet, males exceeded females in the top time use category with $7.7 \%$ of males reporting having spent $\geq 8 \mathrm{~h} / \mathrm{d}$ in front of a screen compared to only $2.5 \%$ of females. The use of a mobile phone was reported by more females than males with about $70 \%$ of females engaging in this activity every day compared to only about $55 \%$ of males. About twice as many females used a mobile phone for $\geq 3 \mathrm{~h} / \mathrm{d}$ compared to males $(12.7 \%$ versus $5.6 \%$ ). Listening to music was the 
most popular activity for both genders and was reported by over $96.4 \%$ females and $88.7 \%$ of males. More females engaged in listening to music for $\geq 3 \mathrm{~h} / \mathrm{d}(36.7 \%)$ compared to males $(24.2 \%)$.

\subsection{Bivariate Analyses}

The bar graphs in Figures 1.1 - 1.6 (Addendum, Figures 1.1 - 1.6) illustrate associations between the time use categories for each media type and IC separately for males and females. Overall, IC prevalences were higher for females in all categories for each type of media in comparison to males except for music in the "never" user category where males had $4.2 \%$ and females $2.9 \%$ prevalence rates. Considering television, both males and females had highest prevalences for IC in the "never" user category (7.5\% for males and $9.9 \%$ for females). Prevalences were $3.7 \%$ and $6.6 \%$ in the $0.5-2 \mathrm{~h} / \mathrm{d}$ category and $5.5 \%$ and $9.4 \%$ in the $\geq 3 \mathrm{~h} / \mathrm{d}$ category. For computer/internet use, both genders had comparable prevalence rates in "never" user (3.5\% and 7.4\%) and $0.5-2 \mathrm{~h} / \mathrm{d}(3.4 \%$ and $7.0 \%)$ categories and highest prevalences were seen in the $\geq 3 \mathrm{~h} / \mathrm{d}$ category with $7.8 \%$ for males and $11.6 \%$ for females. Video gaming had highest prevalence rates for IC for $\geq 3 \mathrm{~h} / \mathrm{d}$ users ( $7.5 \%$ for males and $7.9 \%$ for females) and prevalences for IC were $3.1 \%$ and $6.3 \%$ in the $0.5-2 \mathrm{~h} / \mathrm{d}$ and $4.9 \%$ and $7.6 \%$ in the "never" user categories. Considering total screen time, increasing prevalence rates could be seen over the time use categories for both males and females. In the $\geq 8 \mathrm{~h} / \mathrm{d}$ category, IC prevalences of $8.6 \%$ were seen for males and $12.9 \%$ for females. Prevalences for IC were $5.0 \%$ and $8.6 \%$ in the $0.5-2 \mathrm{~h} / \mathrm{d}$ and $3.3 \%$ and $6.9 \%$ in the "never" user categories. Increased time spent using a mobile phone showed increasing IC prevalences: $3.9 \%$ for males and 5.8\% for females in the "never" user category, $4.4 \%$ and $7.4 \%$ in the $0.5-2 \mathrm{~h} / \mathrm{d}$ category and $5.2 \%$ and $11.0 \%$ in the $\geq 3$ $\mathrm{h} / \mathrm{d}$ category. Listening to music also showed increasing IC prevalence rates for females over the time use categories with $\geq 3 \mathrm{~h} / \mathrm{d}$ showing a prevalence rate of $10.8 \%$. In comparison, a prevalence rate of $6.5 \%$ for IC was seen for males in this category. Prevalences for IC were $3.2 \%$ for males and $5.6 \%$ for females in the $0.5-2 \mathrm{~h} / \mathrm{d}$ and $4.2 \%$ and $2.9 \%$ in the "never" user categories.

\subsection{Logistic Regression Models}

The results of logistic regression analyses for males are shown in Table 2, those for females in Table 3 (Addendum, Table 2 and Table 3). Only the significant results are presented in the following. 
For males, playing video games for $0.5-2 \mathrm{~h} / \mathrm{d}$ reduced the odds for IC in both unadjusted (odds ratio $(\mathrm{OR})=0.59, \mathrm{p}<0.05)$ and adjusted models (adjusted odds ratio $(\mathrm{AOR})=0.60$, $\mathrm{p}<0.05$ ). Whereas the use of computer/internet for $\geq 3 \mathrm{~h} / \mathrm{d}$ was strongly associated with IC in both models $(\mathrm{OR}=2.93, \mathrm{p}<0.01 ; \mathrm{AOR}=2.56, \mathrm{p}<0.05)$. Total screen time of $4-<8 \mathrm{~h} / \mathrm{d}$ in the unadjusted model $(\mathrm{OR}=1.63, \mathrm{p}<0.05)$ and of $\geq 8 \mathrm{~h} / \mathrm{d}$ in unadjusted $(\mathrm{OR}=2.92, \mathrm{p}<0.001)$ and adjusted models $(\mathrm{AOR}=2.45, \mathrm{p}<0.01)$ showed strong and highly significant relationships with IC.

For females, using the computer/internet for $\geq 3 \mathrm{~h} / \mathrm{d}(\mathrm{OR}=1.86, \mathrm{p}<0.05)$ and using a mobile phone for $\geq 3 \mathrm{~h} / \mathrm{d}(\mathrm{OR}=1.98, \mathrm{p}<0.01)$ were associated with IC in the unadjusted models, but were no longer significant when adjusting for age, SES, anxiety/depression and medical condition. Total screen time showed an association with IC in the $\geq 8 \mathrm{~h} / \mathrm{d}$ category in the unadjusted model $(\mathrm{OR}=2.16, \mathrm{p}<0.05)$, but was not significantly associated in the adjusted model. Listening to music for $\geq 3 \mathrm{~h} / \mathrm{d}$ was strongly associated with IC and increased the odds by more than fourfold in both unadjusted $(\mathrm{OR}=5.87, \mathrm{p}<0.01)$ and adjusted models $(\mathrm{AOR}=$ 4.24, $\mathrm{p}<0.05$ ) for females. 


\section{Discussion}

\subsection{Significant results}

Results of this study showed prevalence rates for IC of $4.2 \%$ for males and $7.4 \%$ for females. These percentages lie within the range for previously reported rates of DSM-IV insomnia in adolescents from other countries, which vary between 3.3\% and 10.7\% (Johnson et al. 2006b; Ohayon and Roberts 2001). The gender difference between prevalences of $3.2 \%$ in this study is comparable with findings by Johnson et al. on gender differences in insomnia epidemiology (Johnson et al. 2006b). Moreover, the results of this study showed a remarkable gender difference in the types of electronic media use associated with IC. For males, using the computer/internet for $\geq 3 \mathrm{~h} / \mathrm{d}$ demonstrated a strong significant association with IC in the unadjusted and adjusted models and watching or using a screen device for $\geq 8 \mathrm{~h} / \mathrm{d}$ showed a similarly strong significant relationship. Surprisingly, playing video games for $0.5-2 \mathrm{~h} / \mathrm{d}$ was seen to significantly reduce the odds for having IC for males compared to never playing video games. For females, none of the investigated types of screen media were significantly associated with IC in the adjusted model. Yet, listening to music for $\geq 3 \mathrm{~h} / \mathrm{d}$ demonstrated a strong association and increased the odds significantly for IC more than fourfold in the adjusted model.

\subsection{Tendencies}

In the following, distinctive observations for bivariate and logistic regression analyses will be described in order to point out possible systematic tendencies that were not consistently corroborated by significant results.

\subsubsection{Dose-Response Relationships}

Dose-response relationships with IC were seen for most media types, yet, only highest time use categories of some media types showed significant relationships. These results were presented in chapter 3. In summary, dose-response relationships were found for males for the use of computer/internet, for total screen time and the use of a mobile phone in bivariate analysis. These associations were also seen in logistic regression analyses, except with mobile phones. For females, dose-response relationships were found for the use of computer/internet, for total screen time, the use of a mobile phone and listening to music in both bivariate and 
logistic regression analyses. For some media types, strong increases in IC prevalence and/or OR for IC became relevant only in the highest time use category, as was the case for computer/internet for females for example. These associations without corroboration by statistical significance can be explained by lack of power for some media type time use categories. Despite the large study sample, associations shown could therefore be attributed to chance. Larger samples in future studies could further corroborate these associations.

\subsection{2 "Never" Users}

For males, playing video games for $0.5-2 \mathrm{~h} / \mathrm{d}$ significantly decreased the odds for having IC in the unadjusted and adjusted models (Addendum, Table 2), as described in the significant results chapter 3. This observation was also seen for males concerning television use and listening to music in both logistic regression models, although p-values were not significant. For females, this tendency was appreciated for television use and video gaming in the unadjusted model and only for television use in the adjusted logistic regression model, although without statistical significance (Addendum, Table 3). These observations for males and females were also appreciated in the bivariate model (Addendum, Figures 1.1 - 1.6). where male and female subjects in the "never" category for television use, video gaming and listening to music (only for males) had higher IC prevalences than subjects who engaged in daily media activity. As described above, more statistical power is needed to corroborate these associations.

This observed tendency towards higher occurrence of IC for subjects in the "never" category may be indicative of a confounding factor, which was associated with the "never" category of these media types and also associated with the occurrence of IC. For example, studies have shown that hostile parenting (Rhoades et al. 2012), disturbed familial relationships (Vignau et al. 1997), and poor child-parent relationships (Liu et al. 2000b) show associations to sleep problems in children and adolescents. Furthermore, Adam et al. demonstrated in their study on 2454 children and adolescents in the United States that greater parental warmth and less family conflict were associated with longer sleep times in children (Adam et al. 2007). Therefore, a possible factor for "never" using media may be overly strict parenting with household rules forbidding the use of electronic media and, thus, a parenting style contributing to disruption of sleep. However, this same study also identified clear parental rules as a protective factor for adequate sleep times, especially in adolescents, due to earlier bedtimes. This may depict the circumstance that clearly defined parental rules are in fact promotive of good sleep in children and adolescents, but parental hostility in form of overly 
strict rules (i.e. no electronic media allowed) may result in an emotionally stressful environment for the child and therefore be disruptive of healthy sleep patterns.

\subsection{Comparing Results to Literature}

\subsubsection{Insomnia}

In past studies, sleep problems and insomnia symptoms such as reduced TST, DIS, DMS and daytime sleepiness have been subject to investigation, yet, insomnia as a specific sleep disorder in adolescents has only been studied in few studies for associations to electronic media use. The IC variable in this study included information about DIS and/or DMS and daytime functioning impairments, which are cornerstone symptoms for insomnia diagnosis. Aside from the few studies that investigated insomnia as a specific disorder, which will be discussed below, insomnia symptoms including daytime impairments have not been investigated for associations to electronic media use to date to the current knowledge of the author. This is surprising since hypotheses exist in literature on how arousal through electronic media exposure could affect sleep initiation and arousal mechanisms in particular have been shown to be important factors in insomnia pathogenesis.

The few studies on adolescents in this field that investigated insomnia as a specific sleep disorder were conducted with the intent of assessing problematic or excessive media use with signs of addiction. Yen et al. found subjective insomnia to have a significant association with problematic internet use, but no significant association was seen with problematic mobile phone use in this same study on Taiwanese adolescents (Yen et al. 2008). Another study from China assessed internet addiction in adolescents and insomnia diagnosis determined by the PSQI and found that internet addicts scored significantly poorer on all PSQI components, except for sleep duration (Cheung and Wong 2011). Choi et al. found that Korean adolescents had higher prevalences of insomnia symptoms, which were DIS, DMS and early morning awakening, at higher levels of internet addiction. More males were found to be internet addicts compared to females and internet addicts had poorer health. Furthermore, excessive daytime sleepiness was significantly associated with internet addiction even after adjusting for several sociodemographic, health related and sleep related factors (Choi et al. 2009). Mesquita and Reimao also used the PSQI in order to investigate insomnia in association with the more broad term "computer use" and found that nightly use was associated with overall higher PSQI scores, and, in particular, daytime sleepiness and lower probability of being a “good sleeper" (Mesquita and Reimao 2007). These results are similar and can be compared 
to the results of this study, in which increased use of computer/internet showed associations with IC. Yet, this study was not intended not assess signs of addiction. Furthermore, this study respected gender differences and therefore was able to show different associations for males and females.

Some other studies investigated insomnia symptoms, but did not combine these symptoms in order to achieve a closer approximation of insomnia diagnosis. Gradisar et al. (2013) investigated bedtimes, DIS, DMS and unrefreshing sleep for associations with different electronic media in their study with data from the Sleep in America Poll from 2011, which was a large sample including adolescents. They found that DIS and unrefreshing sleep were significantly associated with multitasking with electronic media devices in the hour before bedtime and that interactive devices (computers/laptops, mobile phones, video games) in particular were accountable for these associations. Furthermore, information on daytime impacts of "not getting enough sleep" on mood, school work, family and social life was also described, but only the prevalences of these daytime impacts were reported in the "Sleep Habits, Sleep Quality" section of the publication and association between daytime functional impairments or a combined variable and media use was not described. This is surprising since Gradisar has put forth some of the leading hypotheses on mechanisms for how media use could affect sleep, and, in particular how cognitive, emotional or physiological arousal could cause sleep disruption (Cain and Gradisar 2010). An approximation of insomnia diagnosis with the investigated sleep variables could have been made in their study, however, Gradisar et al. emphasized DIS in order to explore this hypothesis. They conclude that their results support the arousal hypothesis, but that light and electromagnetic emissions cannot be excluded as causes for DIS. Furthermore, displacement of sleep and devices interrupting the maintenance of sleep (i.e., mobile phones) also could explain associations shown between unrefreshing sleep and interactive media devices.

The study by Arora et al. (2014) shows similarities to this study, since several different media types were investigated. They found that the bedtime use of all six media types (television, video gaming, mobiles phones, music, computer or laptop (for study) internet (social)) were associated with reduced sleep time and frequent early awakening. Furthermore, video gaming and listening to music were associated with significantly prolonged SOL. DIS was related to frequent mobile phone use, video gaming, social networking and listening to music. Interestingly, all media types used at bedtime, except for music and mobile phones, were associated with cognitive difficulty in shutting off the mind before sleep. Unfortunately, the 
authors of this study did not combine any of the insomnia symptoms for an approximation of insomnia diagnosis. Yet, prolonged SOL, DIS, frequent early morning awakening and difficulty shutting off the mind are all classic insomnia symptoms and the different types of media showed different associations with these symptoms, as was also shown in this present study.

When comparing the results of this study with the study by Arora et al. (2014), this study did not show association of IC with increased television use, for example, but the computer/internet use results were similar. Interestingly, Arora et al. showed that listening to music was associated with reduced sleep time, early morning awakening, prolonged SOL and difficulty falling asleep, but not with cognitive difficulty in shutting off the mind before sleep. Screen based media, on the other hand, were all found to be associated with difficulty shutting off the mind. Arora et al. also controlled for gender in their study, yet, this study was able to go further by appreciating gender differences in the types of media associated with IC in separate analyses. Total screen time particularly for males was found to be associated with IC in this study and listening to music was strongly associated with IC for females. These findings support the cognitive arousal hypothesis for screen based media, but not for listening to music. In summary, it is therefore plausible that different types of media, i.e., screen based media, interactive media and music, could be related to insomnia by different pathomechanisms. The nature of the arousal, whether it is cognitive, emotional and/or physiological, might play a role in these distinct pathomechanisms. The choice of certain media content, e.g. violent games for males or emotionally rousing music for females, could further explain gender differences seen in associations. As discussed in chapter 1.2.6, arousal through media use can be seen as a potential precipitating and/or perpetuating factor for insomnia and the results of this study support and further substantiate this hypothesis. Concerning other hypotheses on how media use could affect sleep, displacement of sleep does not sufficiently explain occurrence DIS or DMS seen in this study, as they were key components of the IC variable. Yet, it cannot be excluded that light emissions from a screen could explain associations seen in this study by means of disturbance of melatonin secretion and circadian phase delay.

\subsubsection{Gender, Sleep and Media Use}

As discussed briefly in chapter 1.4.2, a large body of evidence has shown that there is a gender difference in the occurrence of insomnia (Johnson et al. 2006b; Ohayon 2002; Ohayon et al. 2000; Zhang and Wing 2006) and that females suffer more frequently from this disorder. 
A higher prevalence for IC for females was also shown in this study. Gender specific differences were seen in the habitual patterns of electronic media use: descriptive characteristics show that females used a mobile phone and listened to music more frequently than males, whereas males used the computer/internet, played video games and used screen media more frequently than their female counterparts (Addendum, Table 1). Evidence has also shown that there are gender-specific differences not only in quantity, but also in content preferences. For example, a review by Row on media content preferences in European adolescents showed that males tended to watch television shows or films involving action, crime, science fiction, war, science or sports while females preferred to watch music videos, talk shows, daily soaps and classical films. Concerning music, females preferred listening to disco music and mainstream pop whereas males more frequently chose rock music or heavy metal (Roe 2000). When considering the results of this study, the types of media that were shown to be associated with IC displayed a marked gender difference and an approach to this phenomenon will be outlined in the following.

\section{Males and Electronic Gaming}

Studies have shown that physiological arousal states may occur during electronic media use (Wang and Perry 2006), particularly when the media entails violent content, and prolonged violent video gaming has also been shown to affect sleep (King et al. 2012). While video gaming with a game console was not found to be a risk factor for IC in this study, electronic gaming is a common activity that males engage in when using the computer/internet and more than half of popular electronic games have violent content (Rideout et al. 2010). It has furthermore been shown that with increasing screen time usage the gaming component of screen time increases as the television component decreases, particularly for males (Olds et al. 2006). Therefore, the associations seen with computer/internet use and total screen time in this study are possibly a reflection of increased exposure to violent content. Yet, this is merely an assumption since media content was not subject to investigation in this study.

Considering video gaming, the decreased ORs for IC for the $0.5-2 \mathrm{~h} / \mathrm{d}$ category for males are difficult to interpret. It is possible that adolescents in the "never" category had risk factors for IC that were not controlled for by the investigated covariates as previously discussed in chapter 4.2.2. Nonetheless, likelihoods for having IC were increased in the $\geq 3 \mathrm{~h} / \mathrm{d}$ category in adjusted and unadjusted models, although not significant. Increased video gaming may nonetheless be risk factors for insomnia, but a dose-response relationship with a gaming console does not seem to apply. 


\section{Females and Music}

As to listening to music, existing literature does not provide specific hypotheses on how listening to music and sleep problems could interrelate to the author's best knowledge. A well established fact is that music and human emotion are closely connected (Juslin and Vastfjall 2008) and empirical evidence suggests that emotional reactivity and arousal play a substantial role in pathogenesis of insomnia (Baglioni et al. 2010). Some authors have proposed that adolescents use music as a means to deal with unconscious conflicts related to their developmental stage (American Academy of Pediatrics 2009; Roberts and Christensen 2001; Took and Weiss 1994). Adolescents also tend to listen to popular music to counteract feelings of loneliness and to actively influence their emotional state or mood (North et al. 2000; Roberts and Christensen 2001). Especially in this particular age group, a gender difference can be appreciated in the motivations behind listening to music: while males commonly perceive music as a means to boost their energy level or create a more positive image of themselves, females tend to use music to reflect their current emotional state, in particular when feeling lonely or depressed (Roberts and Christensen 2001; Wells 1991). For females, this motivation behind listening to music could possibly explain the results of our study. Emotional, physiological and/or cognitive arousal (i.e. rumination) may be reflected in their music preference and may affect their sleep. Yet, Arora et al. (2014) showed in their study that listening to music before going to bed was not associated with cognitive difficulty in "shutting off", but that this in fact was significantly associated with all of media types involving a screen. Since anxiety/depression was controlled for as a covariate, a more direct effect of listening to music on sleep through emotional states not represented in the anxiety/depression covariate appears reasonable. Future studies might assess possible associations of listening to music with other sleep parameters and explore interrelationships between emotional states, listening to music and sleep problems.

\subsection{Insomnia Complaints Variable}

The variable insomnia complaints (IC) investigated in this study included information on DIS, DMS and feeling "tired and lacking energy" during the past week occurring "often" or "always". This information constitutes an approximation of ICD-10, ICSD-2, DSM-IV or DSM-V insomnia diagnosis. In the following, similarities and differences between IC and these diagnostic classifications will be presented. Furthermore, a conclusion about the investigated IC variable with respect to the purpose of this study will be discussed. 


\subsubsection{Comparison to ICD-10 Classification}

The ICD-10 classification is presented in chapter 1.2.2. ICD-10 defined nonorganic insomnia and IC compare in the three features of DIS and/or DMS and daytime functioning impairments. However, a causal relationship between daytime impairments and the sleep problem cannot be made for the IC variable. Unsatisfactory quantity or quality of sleep and duration and frequency of sleep problems are not included in the IC variable. Yet, anxiety/depression and medical condition were controlled for in the adjusted logistic regression model, and associations to IC shown in this study can be considered a closer approximation of the ICD-10 nonorganic insomnia diagnosis.

\subsubsection{Comparison to ICSD-2 Classification}

Level A criteria for insomnia in the ICSD-2 diagnostic manual comprise the complaint of DIS, DMS, waking up too early or sleep that is chronically unrestorative or poor in quality (for review of ICSD-2 see chapter 1.2.2). Two of these five complaints are covered in the IC variable. Level B criterion, sleep difficulty despite adequate opportunity or circumstances to sleep, is not included in the IC variable. Yet, level $\mathrm{C}$ criteria list possible daytime impairments related to the nighttime sleep difficulty, of which level a (fatigue), level e (daytime sleepiness) and level $\mathrm{f}$ (motivation, energy or initiative reduction) compare in part with "feeling tired or lacking energy" from the IC variable. The IC variable, nonetheless, does not allow for the attribution of a relation between these daytime functioning impairments and the predominant sleep difficulty.

\subsubsection{Comparison to DSM-IV and DSM-V Classifications}

Two of the three level A diagnostic criteria from DSM-IV diagnosis concerning predominant complaints (for review of DSM-IV see chapter 1.2.2), which are DIS or DMS, are covered in the variable IC. The information about "feeling tired or lacking energy" in the IC variable represents a probable impairment of daytime functioning and is therefore not entirely comparable to level B diagnostic criteria of the sleep disturbance (or associated daytime fatigue) causing "distress or impairment in social occupational, or other areas of functioning" of DSM-IV insomnia diagnosis. Furthermore, a causal relation between the sleeping difficulties and the daytime functioning impairments in the IC variable cannot be made, which is stated clearly in the level B DSM-IV criteria. Other diagnostic features of DSM-IV primary insomnia are the exclusion of other sleep-wake disorders (level C) and of sleep disturbance occurring exclusively during the course of another mental disorder (level D) or due to direct effects of a substance or general medical condition (level E). These diagnostic features have 
been addressed in part by adjusting for anxiety/depression and medical condition in logistic regression models. Yet, anxiety/depression and medical condition did not primarily exclude IC. Other sleep disorders (level C) were not controlled for due to lack of information on these conditions in the KiGGS questionnaires. Substance use (caffeine, alcohol and illicit drug use) was addressed as a possible confounding factor, but excluded as a covariate in the adjusted model due to lack of significant confounding associations. Finally, the level A diagnostic feature of duration of symptoms for at least one month is not addressed in the IC variable, since information on duration of symptoms surpassing one week was not included in the KiGGS questionnaire.

Concerning DSM-V diagnosis, level A, level B, level E and level F diagnostic criteria are comparable to DSM-IV and the aforementioned similarities and differences to the IC variable apply (for review of DSM-V see chapter 1.2.2). Yet, duration of symptoms must be longer, at least 3 months, in order to comply with DSM-V insomnia disorder diagnosis and furthermore occur with a frequency of at least 3 nights per week (level C and D criteria). As mentioned before, duration of symptoms lasting longer than one week were not addressed in the IC variable. A new feature of DSM-V is described in level G: insomnia symptoms occurring exclusively in the presence of a mental disorder or medical condition do no longer constitute an exclusion criterion for insomnia diagnosis in the DSM-V diagnostic manual, as was the case previously in the DSM-IV. According to DSM-V, mental disorders and medical conditions can coexist with insomnia under the premise that these disorders and/or conditions do not adequately explain insomnia symptoms.

\subsubsection{Discussion of Insomnia Complaints Variable}

The IC variable in this study is more precise in measuring insomnia disorder than many variables investigated in past studies on electronic media use and insomnia as it includes and combines information on sleep disturbance and on daytime functioning. Yet, DSM-IV or V, ICSD-2 or ICD-10 defined diagnosis was not made. Past research concerning electronic media use and sleep problems in adolescents has focused mainly on sleep time, bedtimes, sleep quality, SOL, insomnia symptoms such as DIS or DMS or daytime sleepiness and DSM-IV defined insomnia. To the knowledge of the author at present, a variable combining the insomnia symptoms DIS, DMS and impairments in daytime functioning has not been investigated in association with electronic media use to date. 
Yet, the data set from KiGGS did not include information about the duration of IC surpassing the length of one week and it is therefore impossible to make implications about acuteness or chronicity of the reported pathological sleep state. Sleep problems and insomnia in particular oftentimes are chronic in nature (Roberts et al. 2008b). Diagnostic criteria concerning duration of insomnia symptoms are included in ICD-10, DSM-IV (one month) and DSM-V (3 months) guidelines. The ICSD-2 general criteria for insomnia do not include information on duration of symptoms, yet, the physician can further refer to one of the 11 listed subtypes of insomnia, duration of symptoms can be specified as acute, subacute or chronic for each subtype. Acute or situational insomnia could have also accounted for the occurrence of IC, yet, the prevalences of IC in this study are comparable with DSM-IV defined insomnia in past epidemiological studies. Therefore, it can be concluded that the IC variable in this study represents a valid and useful approximation of insomnia diagnosis.

Furthermore, the operationalization of the IC variable in this study could have been more precise for measuring only primary insomnia (according to DSM-IV) by designating the presence of the anxiety/depression and/or a medical condition and/or the use of substances affecting sleep as a criterion for exclusion for IC. Secondary insomnias due to these conditions were not excluded in the IC variable and the prevalence rates of IC in descriptive and bivariate analyses therefore comprised both primary and secondary insomnias. Yet, by controlling for anxiety/depression and medical condition in the adjusted logistic regression model (substance use was not included because confounding associations were not substantiated) the ORs in this model represent strengths of association between time use categories for media use and an approximation of primary insomnia in effect. Effect sizes in the adjusted model therefore did not refer to secondary insomnias. The purpose of this study was to measure associations between time use categories for different types of electronic media use and the occurrence of primary insomnia, in the assumption that a cause and effect relationship is a plausible explanation for this association as discussed in chapter 1.2.6. This purpose was achieved by excluding secondary insomnias in the adjusted logistic regression analysis. Yet, when reviewing the operationalization of variables and statistical analysis in retrospect, it can be concluded that anxiety/depression, medical condition and substance use should have been included as criteria of exclusion in the IC variable. This would have resulted in a more precise approximation of DSM-IV defined primary insomnia, or insomnia not occurring as a result of these conditions, in prevalence rates of IC in this study. 
The newly introduced DSM-V classification system, however, has resolved the strict distinction between primary and secondary insomnias from other classification systems and has defined that the presence of a mental disorder or a medical condition does not represent an exclusion criterion for insomnia disorder. Insomnia disorder, mental disorders and medical conditions can coexist according to the DSM-V classification system. In light of this newly introduced classification system, the IC variable in this study in fact can be seen to represent an approximation of DSM-V defined insomnia disorder, although unintentionally, since the DSM-V guidelines had not been published at the time of conception of this study. Controlling for anxiety/depression and medical condition in the adjusted logistic regression analysis was nonetheless necessary in order to exclude confounding of the associations between electronic media use and IC. In effect, the calculated effect sizes in the adjusted model therefore can be seen to represent direct and real associations between time spent with electronic media and IC in the assumption, of course, that all confounding factors were in fact accounted for. The measured effect sizes in the adjusted model can be seen to be uniquely attributable to the independent variable by excluding effects of confounding from known risk factors for insomnia. The intention of this study was to show associations between electronic media use and IC and to eliminate possibility of showing associations that were in fact attributable to other factors. In summary, this was successfully achieved through operationalization of variables and the choice of adjusted logistic regression for statistical analysis.

Lastly, it should be noted that subjects suffering from DSPD could have been rated as positive for IC variable in this study. Cornerstone symptoms of DPSD, as discussed in chapter 1.2.9, are sleep onset delay and daytime sleepiness, which are both symptoms included in the IC variable. Furthermore, the use of electronic media use can also be associated with DSPD.

\subsection{Limitations}

\subsubsection{Time of Day and Bedroom Presence of Media}

This study on sleep and electronic media use specifically examined the amount of time spent per day with different types of media, but the time of day use in relation to bedtime or the presence of electronic media in the bedroom was not subject to investigation. Many children and adolescents use electronic media in their bedrooms before bedtime or even in bed as a pre-sleep activity or sleep aid (Eggermont and Van den Bulck 2006). Therefore, the methods used in this study to investigate media use and adolescent sleep do not allow for conclusions about whether or not evening or nighttime media use show stronger relationships to IC than 
media use throughout the course of a day. Past studies suggest that media use before bedtime can cause sleep disruption. Also, hypotheses for mechanisms by which sleep is disrupted by media use propose proximity to bedtime as a factor causing displacement of sleep (displacement hypothesis), arousal (cognitive, physiological and/or emotional in nature) or shift circadian rhythm through exposure to bright light (Cain and Gradisar 2010). Yet, this study was able to show that increased amounts of time spent per day with certain types of media also showed relationships to IC. This may reflect the fact that adolescents with increased use of media usually spend part of this time using media in the evenings or before bedtime, which has been shown in past studies (Calamaro et al. 2009). Therefore, pre-sleep media use is likely to be accountable for the positive association between media use and IC presented in this study.

\subsubsection{Changes in Media Use Patterns Since 2006}

The KiGGS was conducted from 2003 to 2006 and since then media use and access to electronic media has been shown to be increasing in Western countries. In particular, the introduction of the smart phone has made a significant impact on the modern day media landscape. A large study conducted by the Henry J. Kaiser Family Foundation in the United States titled "Generation M2 - Media in the Lives of 8- to 18-Year Olds" published in 2010 states that "The transformation of the cell phone into a media content delivery platform, and the widespread adoption of the iPod and other MP3 devices, have facilitated an explosion in media consumption among American youth ... The development of mobile media has allowed - indeed, encouraged - young people to find even more opportunities throughout the day for using media, actually expanding the number of hours when they can consume media, often while on the go" (Rideout et al. 2010, p. 3). A considerable increase in media exposure by 2 $1 / 4$ hours compared to similar data collected in 2004 is depicted in this study. American youths were exposed to an average amount of 7.38 hours of media content per day, yet, factoring in the multitasking proportion of $29 \%$ the average amount of exposure per day in fact constituted a total of 10.45 hours. Furthermore, bedroom presence of cable television, DVD players, computers and access to the internet was also shown to be increasing. In Germany, one of the largest studies on media use in adolescence over the time course from 1998 to present has been the JIM study ("Jugend, Information und (Multi-) Media") (Feierabend et al. 2013). This study has been conducted every year on a large representative sample and data on media use in adolescents aged 12 to 19 years is obtained in order to investigate changes in media use patterns over time. Results of this study show, for example, that the average time spent per 
day using the internet in 2013 was 179 minutes, which was an increase of 48 minutes in only one year when compared to results from 2012. 72\% of adolescents in 2013 owned a smart phone with a touch screen and internet access, which represents a device that was not subject to investigation in KiGGS as smart phones were not yet widely available during the time of data collection in 2003 to 2006.

With respect to these changes in the media landscape over the past years it becomes clear that electronic media use patterns today incidentally differ from patterns recorded by the KiGGS from 2003 to 2006. Concerning sleep research, Zimmermann notes in a research brief from 2008 on children's media use and sleep problems for the Henry J. Kaiser Family Foundation that young people's media environments have changed significantly and much evidence on this topic collected in the past needs up-to-date supporting evidence. Newer studies should take the different and evolving media types, contents and times of day of media use into consideration. Yet, this study and other studies from the past provide an important basis for substantiation of associations between electronic media use and sleep disturbance in adolescence. This study was able to demonstrate that different media types showed different associations to IC and that a gender difference was seen in these associations. Increase in media use and changes in media use patterns make further studies in this field of sleep research necessary and, particularly this increase in use in past years, should emphasize the relevance of research in this field. Further studies can use knowledge from this study and past studies in order to further investigate known associations and follow changes over time. For example, the investigation of different media types will become increasingly inappropriate, as various different media contents can now easily be accessed through fewer or even just one media device. Further studies should therefore emphasize media content rather than the media type and, in particular, take multitasking with different types and contents of media into account.

\subsubsection{Cross-Sectional and Questionnaire-Based Design}

Lastly, the cross-sectional and questionnaire based study design of the KiGGS does not allow for implications about a causality between electronic media use and IC in adolescents. This study shows mere associations between these investigated subjective variables at a certain point in time. Causality between independent and dependent variables could be investigated in an experimental study with a longitudinal design, in which media use, arousal and sleep measures, such as vital signs and electroencephalographic measures during media use and sleep, are investigated over a longer period of time. 


\section{Conclusion}

The purpose of this study was to describe associations between time spent per day with different types of electronic media and the occurrence of IC in adolescents. The electronic media types investigated were television use, computer/internet use, video gaming, total screen time (television, computer/internet and video games), mobile phone use, and listening to music. In light of the existing literature on sleep problems and electronic media use in adolescents this study provides an important contribution to research in the following points: Firstly, insomnia symptoms with impairments of daytime functioning have not been investigated as a combined variable for associations with media use, except in few aforementioned studies to the author's current knowledge. Focusing on insomnia is of particular interest in order to substantiate existing hypotheses on how media use and arousal contribute to insomnia etiology. Furthermore, a broad range of different types of electronic media and their associations to IC were investigated. In particular, this study is one of the first to focus on listening to music in association with insomnia symptoms. A detailed investigation of gender differences in associations between different types of electronic media and IC was emphasized. These approaches to this field of sleep research were proven to be valuable, since gender differences in associations to different types of media use were demonstrated in this study: while computer/internet use and total screen time was significantly associated with IC in the adjusted model for males, only listening to music was associated with IC in the adjusted model for females after controlling known confounding factors (age, SES, anxiety/depression and medical condition). The large study sample that this study is based on further substantiates associations with different electronic media types described in previous smaller studies and the extensive data investigated in the KiGGS offered the opportunity to account for known risk factors for insomnia. Causal relationships between electronic media use and insomnia have yet to be investigated in detail. Yet, this study provides a foundation of knowledge about associations between electronic media use and insomnia complaints. Particularly with regard to the increase in media use in adolescents over the past years, results of this study can contribute to progress in this rapidly changing field of important research. 


\section{Addendum}

Table 1. Descriptive Sample Characteristics

\begin{tabular}{|c|c|c|c|c|c|c|}
\hline & \multicolumn{3}{|c|}{ Males $\left(\mathrm{N}^{\dagger}=3862\right)$} & \multicolumn{3}{|c|}{ Females $\left(\mathrm{N}^{\dagger}=3671\right)$} \\
\hline & $\mathrm{N}^{\dagger}$ & $\%$ & $95 \%-\mathrm{Cl}$ & $\mathrm{N}^{\dagger}$ & $\%$ & $95 \%-\mathrm{Cl}$ \\
\hline \multicolumn{7}{|c|}{ Insomnia Complaints } \\
\hline No & 3700 & $95.8 \%$ & $94.9-96.5 \%$ & 3400 & $92.6 \%$ & $91.6-93.6 \%$ \\
\hline Yes & 162 & $4.2 \%$ & $3.5-5.1 \%$ & 271 & $7.4 \%$ & $6.4-8.4 \%$ \\
\hline \multicolumn{7}{|l|}{ Age } \\
\hline 11 & 504 & $12,8 \%$ & $11.9-13.7 \%$ & 481 & $12,8 \%$ & $12.0-13.8 \%$ \\
\hline 12 & 519 & $13,1 \%$ & $12.2-14.1 \%$ & 490 & $13,1 \%$ & $12.1-14.1 \%$ \\
\hline 13 & 542 & $13,7 \%$ & $12.8-14.6 \%$ & 515 & $13,7 \%$ & $12.8-14.7 \%$ \\
\hline 14 & 595 & $15,1 \%$ & $14.2-16.0 \%$ & 564 & $15,1 \%$ & $14.0-16.2 \%$ \\
\hline 15 & 588 & $14,9 \%$ & $13.9-16.0 \%$ & 560 & $14,9 \%$ & $13.7-16.3 \%$ \\
\hline 16 & 605 & $15,3 \%$ & $14.3-16.3 \%$ & 572 & $15,3 \%$ & $14.1-16.4 \%$ \\
\hline 17 & 598 & $15,1 \%$ & $14.0-16.4 \%$ & 565 & $15,1 \%$ & $13.9-16.3 \%$ \\
\hline \multicolumn{7}{|l|}{ SES } \\
\hline high & 966 & $25.5 \%$ & $23.5-27.6 \%$ & 914 & $25.2 \%$ & $23.1-27.3 \%$ \\
\hline middle & 1780 & $47.0 \%$ & $45.0-49.0 \%$ & 1727 & $47.5 \%$ & $45.4-49.7 \%$ \\
\hline low & 1044 & $27.5 \%$ & $25.6-29.6 \%$ & 992 & $27.3 \%$ & $25.5-29.2 \%$ \\
\hline \multicolumn{7}{|c|}{ Anxiety/Depression } \\
\hline normal & 3227 & $84.9 \%$ & $83.5-86.3 \%$ & 2966 & $81.1 \%$ & $79.5-82.7 \%$ \\
\hline borderline & 255 & $6.7 \%$ & $5.8-7.7 \%$ & 285 & $7.8 \%$ & $6.9-8.9 \%$ \\
\hline abnormal & 318 & $8.4 \%$ & $7.4-9.4 \%$ & 404 & $11.0 \%$ & $9.8-12.4 \%$ \\
\hline \multicolumn{7}{|c|}{ Medical Condition } \\
\hline No & 2897 & $74.4 \%$ & $72.8-75.9 \%$ & 2571 & $69.1 \%$ & $67.1-70.9 \%$ \\
\hline Yes & 999 & $25.6 \%$ & $24.1-27.2 \%$ & 1152 & $30.9 \%$ & $29.1-32.9 \%$ \\
\hline \multicolumn{7}{|l|}{ Television } \\
\hline never & 154 & $4.0 \%$ & $3.2-4.9 \%$ & 157 & $4.2 \%$ & $3.5-5.0 \%$ \\
\hline $0.5-2 \mathrm{~h} / \mathrm{d}$ & 2870 & $74.0 \%$ & $72.0-75.8 \%$ & 2670 & $72.2 \%$ & $70.4-73.9 \%$ \\
\hline$\geq 3 \mathrm{~h} / \mathrm{d}$ & 857 & $22.1 \%$ & $20.3-24.0 \%$ & 871 & $23.6 \%$ & $21.9-25.2 \%$ \\
\hline \multicolumn{7}{|c|}{ Computer/Internet } \\
\hline never & 697 & $18.1 \%$ & $16.3-20.0 \%$ & 1101 & $30.1 \%$ & $28.2-32.2 \%$ \\
\hline $0.5-2 \mathrm{~h} / \mathrm{d}$ & 2502 & $65.0 \%$ & $63.0-67.0 \%$ & 2320 & $63.5 \%$ & $61.6-65.3 \%$ \\
\hline$\geq 3 \mathrm{~h} / \mathrm{d}$ & 649 & $16.9 \%$ & $15.4-18.5 \%$ & 233 & $6.4 \%$ & $5.4-7.5 \%$ \\
\hline \multicolumn{7}{|c|}{ Video Games } \\
\hline never & 1909 & $50.3 \%$ & $48.3-52.3 \%$ & 3026 & $83.5 \%$ & $81.9-85.0 \%$ \\
\hline $0.5-2 \mathrm{~h} / \mathrm{d}$ & 1658 & $43.6 \%$ & $41.7-45.6 \%$ & 556 & $15.3 \%$ & $14.0-16.8 \%$ \\
\hline$\geq 3 \mathrm{~h} / \mathrm{d}$ & 232 & $6.1 \%$ & $5.2-7.1 \%$ & 42 & $1.1 \%$ & $0.8-1.6 \%$ \\
\hline \multicolumn{7}{|c|}{ Total Screen Time } \\
\hline $0-<4 \mathrm{~h} / \mathrm{d}$ & 2367 & $62.8 \%$ & $60.5-65.1 \%$ & 2740 & $76.1 \%$ & $74.4-77.8 \%$ \\
\hline $4-<8 \mathrm{~h} / \mathrm{d}$ & 1110 & $29.5 \%$ & $27.5-31.4 \%$ & 769 & $21.4 \%$ & $20.0-22.9 \%$ \\
\hline$\geq 8 \mathrm{~h} / \mathrm{d}$ & 290 & $7.7 \%$ & $6.7-8.8 \%$ & 89 & $2.5 \%$ & $2.0-3.1 \%$ \\
\hline
\end{tabular}




\section{Mobile Phone}

never

0.5-2 h/d

$\geq 3 \mathrm{~h} / \mathrm{d}$

Music

never

$0.5-2 \mathrm{~h} / \mathrm{d}$

$\geq 3 \mathrm{~h} / \mathrm{d}$
1747

1890

214

$45.4 \%$

$49.1 \%$

$43.2-47.6 \%$

$46.9-51.2 \%$

1112

2097

$30.2 \%$

$28.3-32.3 \%$

$5.6 \%$

$4.8-6.5 \%$

468

$57.0 \%$

$55.0-59.0 \%$

$12.7 \% \quad 11.5-14.0 \%$

\begin{tabular}{cccccc}
434 & $11.3 \%$ & $10.2-12.5 \%$ & 129 & $3.5 \%$ & $2.9-4.3 \%$ \\
2487 & $64.5 \%$ & $62.7-66.3 \%$ & 2200 & $59.7 \%$ & $57.8-61.6 \%$ \\
934 & $24.2 \%$ & $22.6-26.0 \%$ & 1353 & $36.7 \%$ & $34.8-38.7 \%$ \\
\hline
\end{tabular}

$+\mathrm{N}$ values were weighted to correct for geographical, age, and gender disparities between the sample and the country's general population. Thus, the sum of Ns for some characteristics may differ from the total $\mathrm{N}$ of the sample.

Table 2. Logistic Regression Models

Electronic media use and insomnia complaints in a representative sample of $11-17$ year-old German males

\begin{tabular}{|c|c|c|c|c|c|c|}
\hline \multirow[t]{2}{*}{ MALES } & \multicolumn{3}{|c|}{ Unadjusted Model } & \multicolumn{3}{|c|}{ Adjusted Model ${ }^{\dagger}$} \\
\hline & OR & $95 \%-\mathrm{Cl}$ & $\mathbf{P}$ & OR & $95 \%-\mathrm{Cl}$ & $\mathbf{P}$ \\
\hline \multicolumn{7}{|l|}{ Television } \\
\hline never & 1.00 & - & - & 1.00 & - & - \\
\hline $0.5-2 \mathrm{~h} / \mathrm{d}$ & 0.47 & $0.22-1.01$ & 0.052 & 0.52 & $0.22-1.23$ & 0.134 \\
\hline$\geq 3 \mathrm{~h} / \mathrm{d}$ & 0.77 & $0.34-1.68$ & 0.491 & 0.71 & $0.29-1.77$ & 0.463 \\
\hline \multicolumn{7}{|c|}{ Video Games } \\
\hline never & 1.00 & - & - & 1.00 & - & - \\
\hline $0.5-2 \mathrm{~h} / \mathrm{d}$ & 0.59 & $0.38-0.91$ & 0.018 & 0.60 & $0.38-0.93$ & 0.024 \\
\hline$\geq 3 \mathrm{~h} / \mathrm{d}$ & 1.53 & $0.80-2.94$ & 0.198 & 1.44 & $0.73-2.85$ & 0.299 \\
\hline \multicolumn{7}{|c|}{ Computer/Internet } \\
\hline never & 1.00 & - & - & 1.00 & - & - \\
\hline $0.5-2 \mathrm{~h} / \mathrm{d}$ & 1.17 & $0.61-2.25$ & 0.637 & 1.22 & $0.63-2.36$ & 0.549 \\
\hline$\geq 3 \mathrm{~h} / \mathrm{d}$ & 2.93 & $1.38-6.22$ & 0.005 & 2.56 & $1.18-5.55$ & 0.017 \\
\hline \multicolumn{7}{|c|}{ Total Screen Time } \\
\hline $0-<4 \mathrm{~h} / \mathrm{d}$ & 1.00 & - & - & 1.00 & - & - \\
\hline $4-<8 \mathrm{~h} / \mathrm{d}$ & 1.63 & $1.02-2.61$ & 0.043 & 1.44 & $0.87-2.37$ & 0.154 \\
\hline$\geq 8 \mathrm{~h} / \mathrm{d}$ & 2.92 & $1.65-5.18$ & $<0.001$ & 2.45 & $1.38-4.35$ & 0.002 \\
\hline \multicolumn{7}{|c|}{ Mobile phone } \\
\hline never & 1.00 & - & - & 1.00 & - & - \\
\hline $0.5-2 \mathrm{~h} / \mathrm{d}$ & 1.25 & $0.84-1.87$ & 0.273 & 1.02 & $0.68-1.53$ & 0.924 \\
\hline$\geq 3 \mathrm{~h} / \mathrm{d}$ & 1.01 & $0.39-2.64$ & 0.984 & 0.71 & $0.24-2.12$ & 0.542 \\
\hline \multicolumn{7}{|l|}{ Music } \\
\hline never & 1.00 & - & - & 1.00 & - & - \\
\hline $0.5-2 \mathrm{~h} / \mathrm{d}$ & 0.76 & $0.42-1.38$ & 0.367 & 0.63 & $0.35-1.13$ & 0.121 \\
\hline$\geq 3 \mathrm{~h} / \mathrm{d}$ & 1.71 & $0.87-3.38$ & 0.120 & 1.23 & $0.62-2.48$ & 0.553 \\
\hline
\end{tabular}

adjusted for age, socio-economic status, anxiety/depression, medical condition 
Table 3. Logistic Regression Models

Electronic media use and insomnia complaints in a representative sample of $11-17$ year-old German females

\begin{tabular}{|c|c|c|c|c|c|c|}
\hline \multirow[t]{2}{*}{ FEMALES } & \multicolumn{3}{|c|}{ Unadjusted Model } & \multicolumn{3}{|c|}{ Adjusted Model ${ }^{\dagger}$} \\
\hline & OR & $95 \%-\mathrm{Cl}$ & $\mathbf{P}$ & OR & $95 \%-\mathrm{Cl}$ & $\mathbf{P}$ \\
\hline \multicolumn{7}{|l|}{ Television } \\
\hline never & 1.00 & - & - & 1.00 & - & - \\
\hline $0.5-2 \mathrm{~h} / \mathrm{d}$ & 0.63 & $0.32-1.24$ & 0.181 & 0.65 & $0.32-1.32$ & 0.235 \\
\hline$\geq 3 \mathrm{~h} / \mathrm{d}$ & 0.95 & $0.48-1.91$ & 0.893 & 0.92 & $0.44-1.90$ & 0.820 \\
\hline \multicolumn{7}{|c|}{ Video Games } \\
\hline never & 1.00 & - & - & 1.00 & - & - \\
\hline $0.5-2 \mathrm{~h} / \mathrm{d}$ & 0.87 & $0.54-1.38$ & 0.542 & 1.03 & $0.63-1.70$ & 0.905 \\
\hline$\geq 3 \mathrm{~h} / \mathrm{d}$ & 1.13 & $0.31-4.08$ & 0.853 & 1.24 & $0.36-4.36$ & 0.733 \\
\hline \multicolumn{7}{|c|}{ Computer/Internet } \\
\hline never & 1.00 & - & - & 1.00 & - & - \\
\hline $0.5-2 \mathrm{~h} / \mathrm{d}$ & 1.04 & $0.73-1.47$ & 0.847 & 1.03 & $0.73-1.45$ & 0.873 \\
\hline$\geq 3 \mathrm{~h} / \mathrm{d}$ & 1.86 & $1.11-3.12$ & 0.018 & 1.57 & $0.91-2.70$ & 0.102 \\
\hline \multicolumn{7}{|c|}{ Total Screen Time } \\
\hline $0-<4 \mathrm{~h} / \mathrm{d}$ & 1.00 & - & - & 1.00 & - & - \\
\hline $4-<8 \mathrm{~h} / \mathrm{d}$ & 1.35 & $0.93-1.95$ & 0.117 & 1.27 & $0.86-1.88$ & 0.224 \\
\hline$\geq 8 \mathrm{~h} / \mathrm{d}$ & 2.16 & $1.04-4.48$ & 0.039 & 2.04 & $0.97-4.31$ & 0.062 \\
\hline \multicolumn{7}{|c|}{ Mobile phone } \\
\hline never & 1.00 & - & - & 1.00 & - & - \\
\hline $0.5-2 \mathrm{~h} / \mathrm{d}$ & 1.33 & $0.94-1.89$ & 0.110 & 1.01 & $0.69-1.48$ & 0.949 \\
\hline$\geq 3 \mathrm{~h} / \mathrm{d}$ & 1.98 & $1.25-3.14$ & 0.004 & 1.31 & $0.78-2.21$ & 0.312 \\
\hline \multicolumn{7}{|l|}{ Music } \\
\hline never & 1.00 & - & - & 1.00 & - & - \\
\hline $0.5-2 \mathrm{~h} / \mathrm{d}$ & 2.84 & $0.78-10.30$ & 0.113 & 2.44 & $0.65-9.12$ & 0.184 \\
\hline$\geq 3 \mathrm{~h} / \mathrm{d}$ & 5.87 & $1.69-20.35$ & 0.005 & 4.24 & $1.18-15.28$ & 0.027 \\
\hline
\end{tabular}

adjusted for age, socio-economic status, anxiety/depression, medical condition 
Figures 1.1 - 1.6 Bivariate Analyses

Figure 1.1

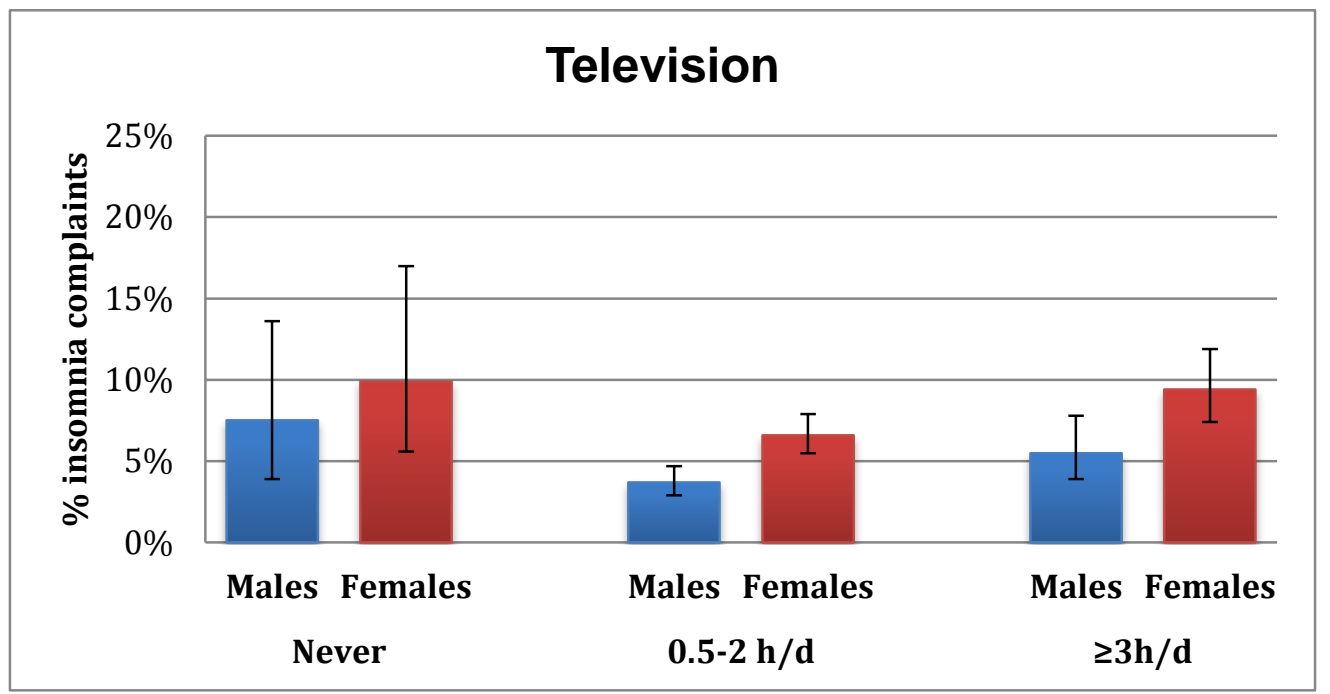

Figure 1.2

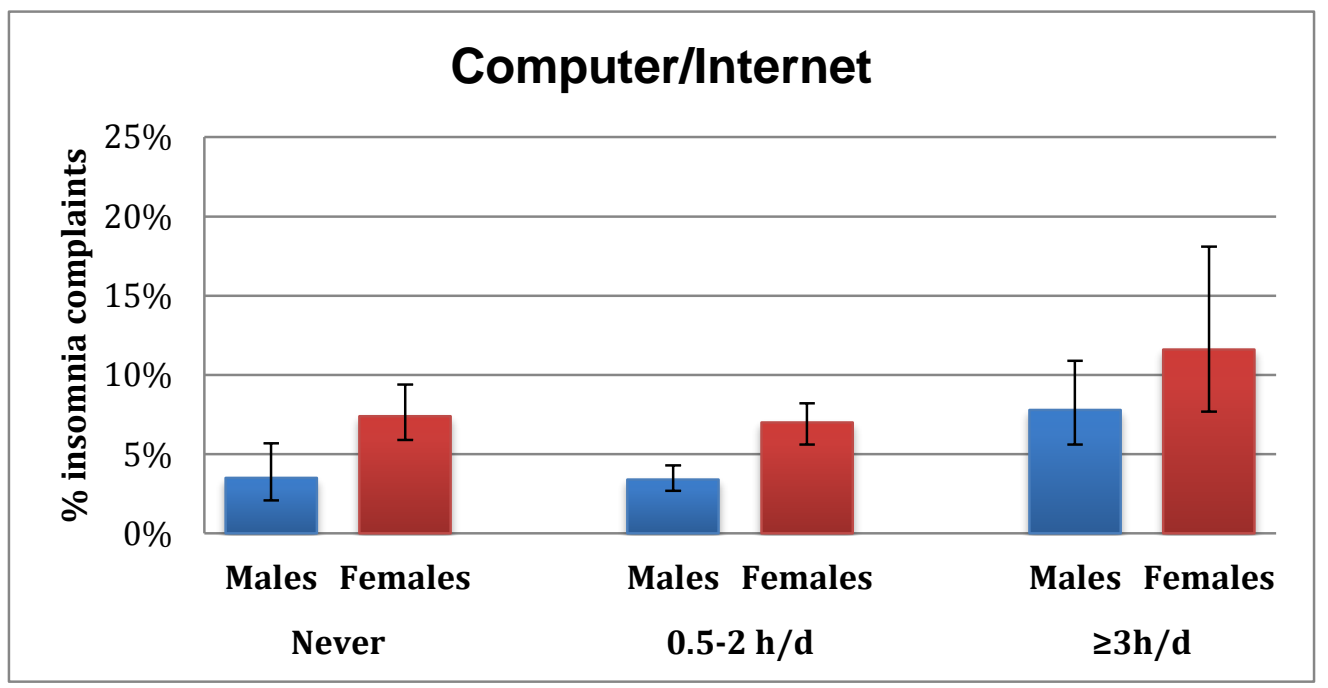


Figure 1.3

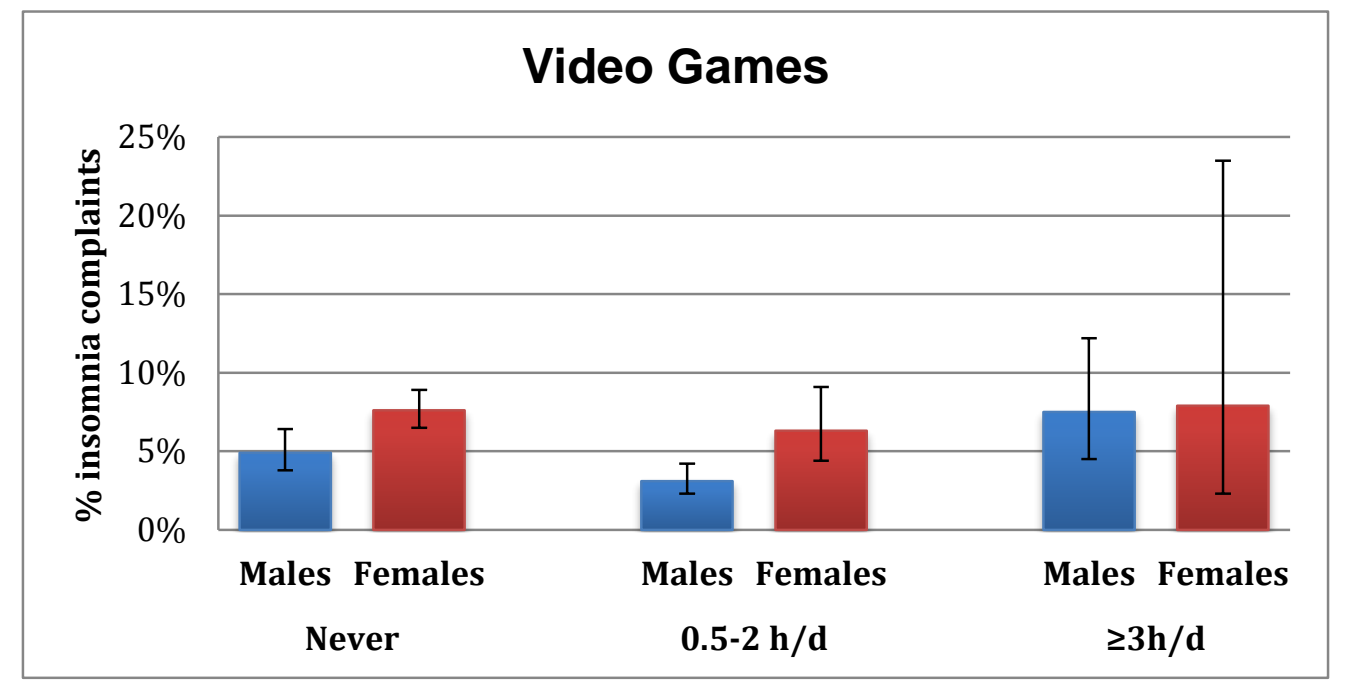

Figure 1.4

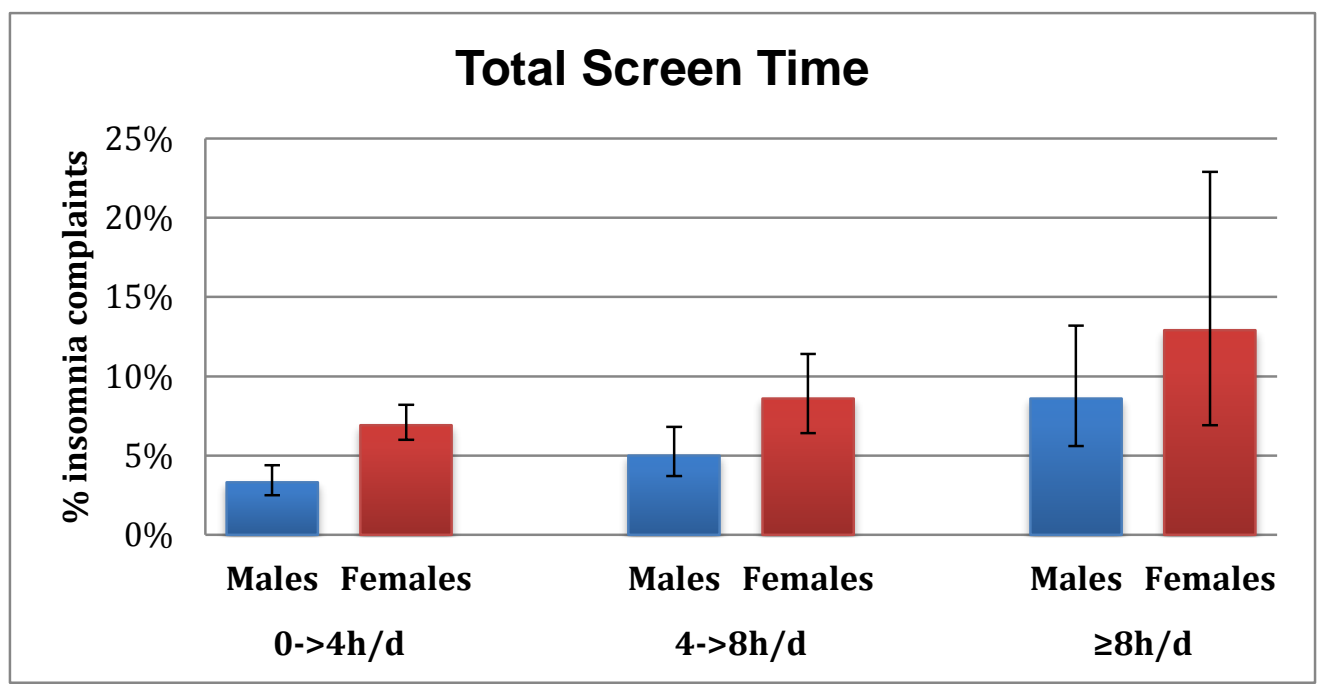

Figure 1.5

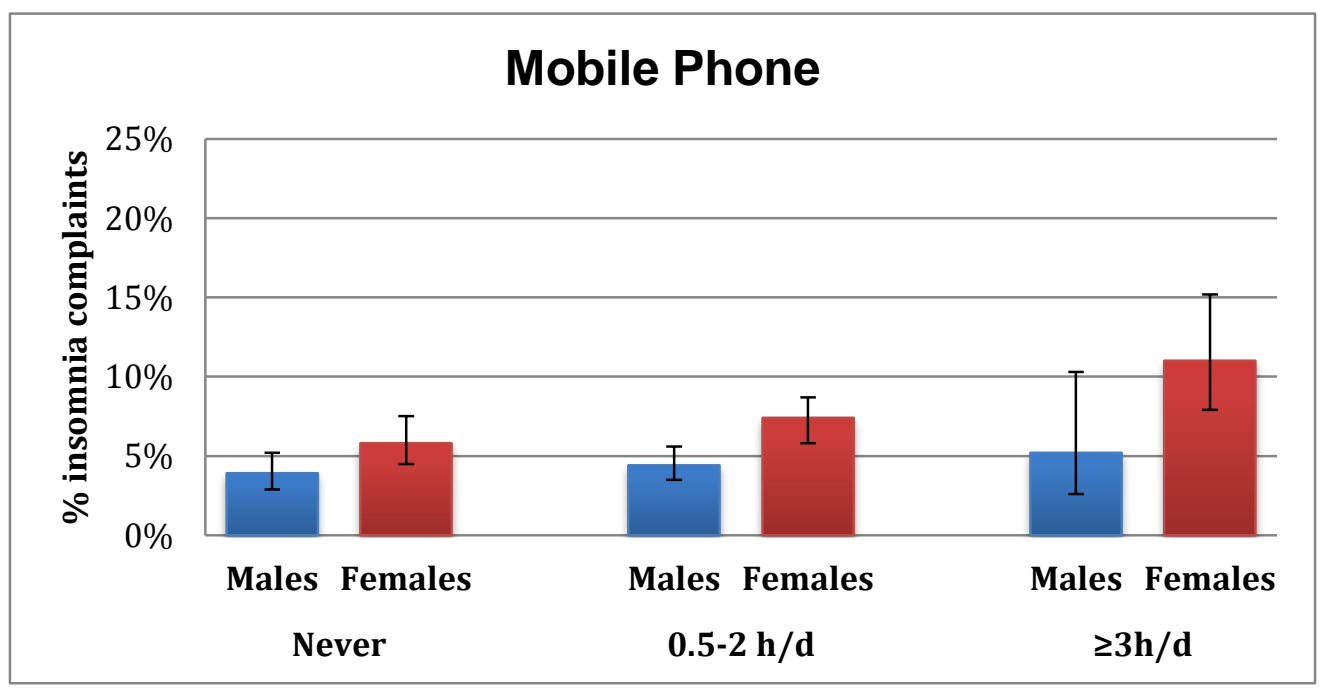


Figure 1.6

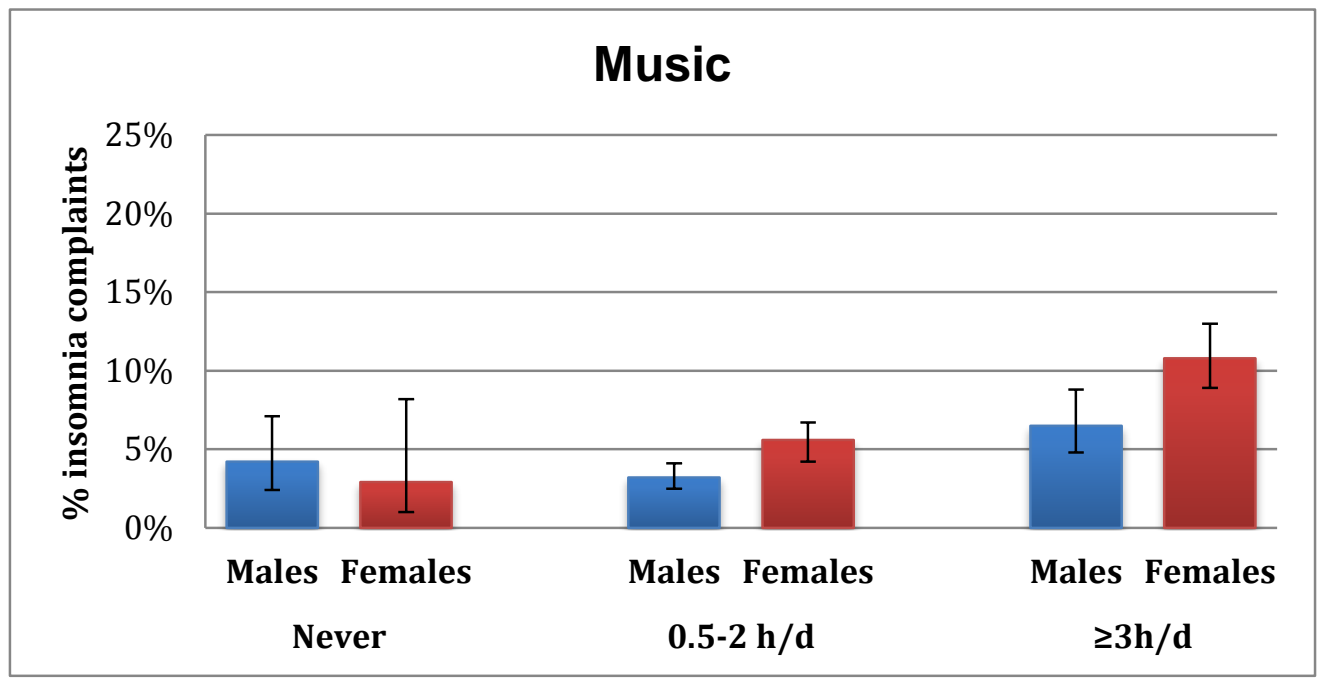




\section{Abbreviations}

\begin{tabular}{ll}
\hline AASM & American Academy of Sleep Medicine \\
APA & American Psychiatric Association \\
BZRAs & Benzodiazepine Receptor Agonists \\
CBT & Cognitive Behavioral Therapy \\
CI & Confidence Interval \\
CSHCN & Children with Special Health Care Needs \\
DIS & Difficulty Initiating Sleep \\
DMS & Difficulty Maintaining Sleep \\
DSM & Diagnostik and Statistical Manual of Mental Disorders \\
DSPD & Delayed Sleep Phase Disorder \\
IC & Insomnia Complaints \\
ICD & International Classification of Diseases \\
ICSD & International Classification of Sleep Disorders \\
KiGGS & German Health Interview and Examination Survey for \\
& Children and Adolescents (in German: Kinder- und \\
AOR & Jugendgesundheitssurvey) \\
OR & Adjusted Odds Ratio \\
PSG & Odds Ratio \\
PSQI & Polysomnography \\
SDQ & Pittsburgh Sleep Quality Index \\
SOL & Strenghts and Difficulties Questionnaire \\
TST & Socioeconomic Status \\
& Sleep Onset Latency \\
&
\end{tabular}




\section{Bibliography}

Adam EK, Snell EK, Pendry P (2007): Sleep timing and quantity in ecological and family context: a nationally representative time-diary study. J Fam Psychol 21(1), 4-19

Alexandru G, Michikazu S, Shimako H, Xiaoli C, Hitomi K, Takashi Y, Robert WW, Sadanobu K (2006): Epidemiological aspects of self-reported sleep onset latency in Japanese junior high school children. J Sleep Res 15(3), 266-275

American Academy of Pediatrics (2009): Policy statement--Impact of music, music lyrics, and music videos on children and youth. Pediatrics 124(5), 1488-1494

American Academy of Sleep Medicine (AASM): The International Classification of Sleep Disorders: ICSD-2; American Academy of Sleep Medicine, Westchester, Illinois 2005

American Psychiatric Association (APA): Diagnostic and Statistical Manual of Mental Disorders: DSM-IV-TR; The American Psychiatric Association, Washington, DC 2000

American Psychiatric Association (APA): Diagnostic and Statistical Manual of Mental Disorders: DSM-V; The American Psychiatric Association, Arlington, VA 2013

Ancoli-Israel S (2006): The impact and prevalence of chronic insomnia and other sleep disturbances associated with chronic illness. Am J Manag Care 12(8 Suppl), S221-229

Arora T, Broglia E, Thomas GN, Taheri S (2014): Associations between specific technologies and adolescent sleep quantity, sleep quality, and parasomnias. Sleep Med 15(2), 240247

Baglioni C, Spiegelhalder K, Lombardo C, Riemann D (2010): Sleep and emotions: a focus on insomnia. Sleep Med Rev 14(4), 227-238

Baglioni C, Battagliese G, Feige B, Spiegelhalder K, Nissen C, Voderholzer U, Lombardo C, Riemann D (2011): Insomnia as a predictor of depression: a meta-analytic evaluation of longitudinal epidemiological studies. J Affect Disord 135(1-3), 10-19

Bartlett DJ, Biggs SN, Armstrong SM (2013): Circadian rhythm disorders among adolescents: assessment and treatment options. Med J Aust 199(8), S16-20

Bastien CH, Vallieres A, Morin CM (2001): Validation of the Insomnia Severity Index as an outcome measure for insomnia research. Sleep Med 2(4), 297-307

Bonnet MH, Arand DL (1998): Heart rate variability in insomniacs and matched normal sleepers. Psychosom Med 60(5), 610-615

Bonnet MH, Arand DL (2000): The impact of music upon sleep tendency as measured by the multiple sleep latency test and maintenance of wakefulness test. Physiol Behav $\underline{71(5),}$ 485-492

Bonnet MH, Arand DL (2003): Situational insomnia: consistency, predictors, and outcomes. Sleep 26(8), 1029-1036

Bonnet MH, Arand DL (2010): Hyperarousal and insomnia: state of the science. Sleep Med Rev 14(1), 9-15

Bootzin RR (1973). Stimulus Control Treatment for Insomnia. Proceedings of the 80th Annual Convention of the American Psychological Association. Honolulu, Hawaii, American Psychological Association 7, 395-396.

Brown JD, L'Engle KL, Pardun CJ, Guo G, Kenneavy K, Jackson C (2006): Sexy media matter: exposure to sexual content in music, movies, television, and magazines predicts black and white adolescents' sexual behavior. Pediatrics 117(4), 1018-1027 
Brunborg GS, Mentzoni RA, Molde H, Myrseth H, Skouveroe KJ, Bjorvatn B, Pallesen S (2011): The relationship between media use in the bedroom, sleep habits and symptoms of insomnia. J Sleep Res 20(4), 569-575

Buysse DJ, Reynolds CF, 3rd, Monk TH, Berman SR, Kupfer DJ (1989): The Pittsburgh Sleep Quality Index: a new instrument for psychiatric practice and research. Psychiatry Res 28(2), 193-213

Cain N, Gradisar M (2010): Electronic media use and sleep in school-aged children and adolescents: A review. Sleep Med 11(8), 735-742

Calamaro CJ, Mason TB, Ratcliffe SJ (2009): Adolescents living the 24/7 lifestyle: effects of caffeine and technology on sleep duration and daytime functioning. Pediatrics $\underline{123}(6)$, e1005-1010

Canals J, Domenech E, Carbajo G, Blade J (1997): Prevalence of DSM-III-R and ICD-10 psychiatric disorders in a Spanish population of 18-year-olds. Acta Psychiatr Scand $\underline{96}(4), 287-294$

Cappuccio FP, Taggart FM, Kandala NB, Currie A, Peile E, Stranges S, Miller MA (2008): Meta-analysis of short sleep duration and obesity in children and adults. Sleep $\underline{31}(5)$, 619-626

Carskadon MA (2011): Sleep in adolescents: the perfect storm. Pediatr Clin North Am 58(3), 637-647

Carskadon MA, Harvey K, Duke P, Anders TF, Litt IF, Dement WC (1980): Pubertal changes in daytime sleepiness. Sleep 2(4), 453-460

Chaput JP, Brunet M, Tremblay A (2006): Relationship between short sleeping hours and childhood overweight/obesity: results from the 'Quebec en Forme' Project. Int J Obes (Lond) 30(7), 1080-1085

Chen MY, Wang EK, Jeng YJ (2006): Adequate sleep among adolescents is positively associated with health status and health-related behaviors. BMC Public Health $\underline{6}, 59$

Cheung LM, Wong WS (2011): The effects of insomnia and internet addiction on depression in Hong Kong Chinese adolescents: an exploratory cross-sectional analysis. J Sleep Res 20(2), 311-317

Choi K, Son H, Park M, Han J, Kim K, Lee B, Gwak H (2009): Internet overuse and excessive daytime sleepiness in adolescents. Psychiatry Clin Neurosci 63(4), 455-462

Chung KF, Cheung MM (2008): Sleep-wake patterns and sleep disturbance among Hong Kong Chinese adolescents. Sleep 31(2), 185-194

Crowley SJ, Acebo C, Carskadon MA (2007): Sleep, circadian rhythms, and delayed phase in adolescence. Sleep Med $\underline{8}(6), 602-612$

Curcio G, Ferrara M, De Gennaro L (2006): Sleep loss, learning capacity and academic performance. Sleep Med Rev 10(5), 323-337

Daley M, Morin CM, LeBlanc M, Gregoire JP, Savard J (2009): The economic burden of insomnia: direct and indirect costs for individuals with insomnia syndrome, insomnia symptoms, and good sleepers. Sleep 32(1), 55-64

Dewald JF, Meijer AM, Oort FJ, Kerkhof GA, Bogels SM (2010): The influence of sleep quality, sleep duration and sleepiness on school performance in children and adolescents: A meta-analytic review. Sleep Med Rev 14(3), 179-189

Dijk DJ, Cajochen C, Borbely AA (1991): Effect of a single 3-hour exposure to bright light on core body temperature and sleep in humans. Neurosci Lett 121(1-2), 59-62

Dorofaeff TF, Denny S (2006): Sleep and adolescence. Do New Zealand teenagers get enough? J Paediatr Child Health 42(9), 515-520

Drake C, Richardson G, Roehrs T, Scofield H, Roth T (2004): Vulnerability to stress-related sleep disturbance and hyperarousal. Sleep 27(2), 285-291

Drake CL, Friedman NP, Wright KP, Jr., Roth T (2011): Sleep reactivity and insomnia: genetic and environmental influences. Sleep $\underline{34}(9), 1179-1188$ 
Drewes AM, Nielsen KD, Hansen B, Taagholt SJ, Bjerregard K, Svendsen L (2000): A longitudinal study of clinical symptoms and sleep parameters in rheumatoid arthritis. Rheumatology (Oxford) 39(11), 1287-1289

Dworak M, Schierl T, Bruns T, Struder HK (2007): Impact of singular excessive computer game and television exposure on sleep patterns and memory performance of schoolaged children. Pediatrics $\underline{120}(5), 978-985$

Eggermont S, Van den Bulck J (2006): Nodding off or switching off? The use of popular media as a sleep aid in secondary-school children. J Paediatr Child Health $\underline{42}(7-8)$, $428-433$

Espie CA, Broomfield NM, MacMahon KM, Macphee LM, Taylor LM (2006): The attentionintention-effort pathway in the development of psychophysiologic insomnia: a theoretical review. Sleep Med Rev 10(4), 215-245

Feierabend S, Karg U, Rathgeb T (2013). 15 Jahre JIM-Studie. Stuttgart, Medienpädagogischer Forschungsverbund Südwest. Available at: http://www.mpfs.de/index.php?id=584; accessed March 13, 2014

Fernandez-Mendoza J, Vela-Bueno A, Vgontzas AN, Ramos-Platon MJ, OlavarrietaBernardino S, Bixler EO, De la Cruz-Troca JJ (2010): Cognitive-emotional hyperarousal as a premorbid characteristic of individuals vulnerable to insomnia. Psychosom Med 72(4), 397-403

Foley LS, Maddison R, Jiang Y, Marsh S, Olds T, Ridley K (2013): Presleep activities and time of sleep onset in children. Pediatrics $131(2), 276-282$

Foundation NS: 2006 Sleep in America Poll. Foundation NS, Washington, DC 2006

Fredriksen K, Rhodes J, Reddy R, Way N (2004): Sleepless in Chicago: tracking the effects of adolescent sleep loss during the middle school years. Child Dev 75(1), 84-95

Gaina A, Sekine M, Kanayama H, Sengoku K, Yamagami T, Kagamimori S (2005): Shortlong sleep latency and associated factors in Japanese junior high school children. Sleep and Biological Rhythms $\underline{3}(3), 162-165$

Gaina A, Sekine M, Hamanishi S, Chen X, Wang H, Yamagami T, Kagamimori S (2007): Daytime sleepiness and associated factors in Japanese school children. J Pediatr $151(5), 518-522,522$ e $511-514$

Gau SS, Soong WT, Merikangas KR (2004): Correlates of sleep-wake patterns among children and young adolescents in Taiwan. Sleep 27(3), 512-519

Goodman R (1997): The Strengths and Difficulties Questionnaire: a research note. J Child Psychol Psychiatry 38(5), 581-586

Gradisar M, Crowley SJ (2013): Delayed sleep phase disorder in youth. Curr Opin Psychiatry $\underline{26}(6), 580-585$

Gradisar M, Gardner G, Dohnt H (2011): Recent worldwide sleep patterns and problems during adolescence: a review and meta-analysis of age, region, and sleep. Sleep Med $\underline{12}(2), 110-118$

Gradisar M, Wolfson AR, Harvey AG, Hale L, Rosenberg R, Czeisler CA (2013): The sleep and technology use of Americans: findings from the National Sleep Foundation's 2011 Sleep in America poll. J Clin Sleep Med 9 (12), 1291-1299

Hajak G (2001): Epidemiology of severe insomnia and its consequences in Germany. Eur Arch Psychiatry Clin Neurosci 251(2), 49-56

Harada T, Morikuni M, Yoshii S, Yamashita Y, Takeuchi H (2002): Usage of Mobile Phone in The Evening or at Night Makes Japanese Students Evening-typed ad Night Sleep Uncomfortable. Sleep and Hypnosis $\underline{4}(4), 149-153$

Harvey AG (2002): A cognitive model of insomnia. Behav Res Ther 40(8), 869-893

Harvey AG, Murray G, Chandler RA, Soehner A (2011): Sleep disturbance as transdiagnostic: consideration of neurobiological mechanisms. Clin Psychol Rev $\underline{31}(2), 225-235$ 
Harvey AG, Asarnow LD: Insomnia; in: The Wiley Handbook of Cognitive Behavioral Therapy. Edited by Hofman SG; John Wiley \& Sons, Ltd. , Hoboken, NJ 2014, 541565

Hayashino Y, Fukuhara S, Suzukamo Y, Okamura T, Tanaka T, Ueshima H (2007): Relation between sleep quality and quantity, quality of life, and risk of developing diabetes in healthy workers in Japan: the High-risk and Population Strategy for Occupational Health Promotion (HIPOP-OHP) Study. BMC Public Health $\underline{7}, 129$

Haynes SN, Adams A, Franzen M (1981): The effects of presleep stress on sleep-onset insomnia. J Abnorm Psychol 90(6), 601-606

Heath M, Sutherland C, Bartel K, Gradisar M, Williamson P, Lovato N, Micic G (2014): Does one hour of bright or short-wavelength filtered tablet screenlight have a meaningful effect on adolescents' pre-bedtime alertness, sleep, and daytime functioning? Chronobiol Int,

Higuchi S, Motohashi Y, Liu Y, Ahara M, Kaneko Y (2003): Effects of VDT tasks with a bright display at night on melatonin, core temperature, heart rate, and sleepiness. $\mathrm{J}$ Appl Physiol 94(5), 1773-1776

Higuchi S, Motohashi Y, Liu Y, Maeda A (2005): Effects of playing a computer game using a bright display on presleep physiological variables, sleep latency, slow wave sleep and REM sleep. J Sleep Res 14(3), 267-273

Hysing M, Pallesen S, Stormark KM, Lundervold AJ, Sivertsen B (2013): Sleep patterns and insomnia among adolescents: a population-based study. J Sleep Res 22(5), 549-556

Iglowstein I, Jenni OG, Molinari L, Largo RH (2003): Sleep duration from infancy to adolescence: reference values and generational trends. Pediatrics 111(2), 302-307

Ivarsson M, Anderson M, Akerstedt T, Lindblad F (2009a): Playing a violent television game does not affect saliva cortisol. Acta Paediatr 98(6), 1052-1053

Ivarsson M, Anderson M, Akerstedt T, Lindblad F (2009b): Playing a violent television game affects heart rate variability. Acta Paediatr 98(1), 166-172

Johnson EO, Breslau N (2001): Sleep problems and substance use in adolescence. Drug Alcohol Depend 64(1), 1-7

Johnson EO, Roth T, Breslau N (2006a): The association of insomnia with anxiety disorders and depression: exploration of the direction of risk. J Psychiatr Res 40(8), 700-708

Johnson EO, Roth T, Schultz L, Breslau N (2006b): Epidemiology of DSM-IV insomnia in adolescence: lifetime prevalence, chronicity, and an emergent gender difference. Pediatrics 117(2), e247-256

Johnson JG, Cohen P, Smailes EM, Kasen S, Brook JS (2002): Television viewing and aggressive behavior during adolescence and adulthood. Science 295(5564), 2468-2471

Johnson JG, Cohen P, Kasen S, First MB, Brook JS (2004): Association between television viewing and sleep problems during adolescence and early adulthood. Arch Pediatr Adolesc Med 158(6), 562-568

Juslin PN, Vastfjall D (2008): Emotional responses to music: the need to consider underlying mechanisms. Behav Brain Sci 31(5), 559-575; discussion 575-621

Kaneita Y, Ohida T, Osaki Y, Tanihata T, Minowa M, Suzuki K, Wada K, Kanda H, Hayashi $\mathrm{K}$ (2006): Insomnia among Japanese adolescents: a nationwide representative survey. Sleep 29(12), 1543-1550

Katz DA, McHorney CA (2002): The relationship between insomnia and health-related quality of life in patients with chronic illness. J Fam Pract 51(3), 229-235

King DL, Gradisar M, Drummond A, Lovato N, Wessel J, Micic G, Douglas P, Delfabbro P (2012): The impact of prolonged violent video-gaming on adolescent sleep: an experimental study. J Sleep Res, 
Knutson KL, Lauderdale DS (2009): Sociodemographic and behavioral predictors of bed time and wake time among US adolescents aged 15 to 17 years. J Pediatr 154(3), 426-430, 430 e 421

Kok FW, Westenberg HG, Thijssen JH, van Ree JM (1995): Endocrine and cardiovascular responses to a series of graded physical and psychological stress stimuli in healthy volunteers. Eur Neuropsychopharmacol $\underline{5}(4), 515-522$

Kubota T, Uchiyama M, Suzuki H, Shibui K, Kim K, Tan X, Tagaya H, Okawa M, Inoue S (2002): Effects of nocturnal bright light on saliva melatonin, core body temperature and sleep propensity rhythms in human subjects. Neurosci Res $\underline{42}(2), 115-122$

Kurth BM, Kamtsiuris P, Holling H, Schlaud M, Dolle R, Ellert U, Kahl H, Knopf H, Lange M, Mensink GB et al. (2008): The challenge of comprehensively mapping children's health in a nation-wide health survey: design of the German KiGGS-Study. BMC Public Health $\underline{8}, 196$

Lam LT, Yang L (2008): Duration of sleep and ADHD tendency among adolescents in China. J Atten Disord 11(4), 437-444

Lampert T, Sygusch R, Schlack R (2007): [Use of electronic media in adolescence. Results of the German Health Interview and Examination Survey for Children and Adolescents (KiGGS)]. Bundesgesundheitsblatt Gesundheitsforschung Gesundheitsschutz 50(5-6), 643-652

Leger D, Guilleminault C, Bader G, Levy E, Paillard M (2002): Medical and socioprofessional impact of insomnia. Sleep 25(6), 625-629

Lichstein KL (2006): Secondary insomnia: a myth dismissed. Sleep Med Rev 10(1), 3-5

Liu X, Zhou H (2002): Sleep duration, insomnia and behavioral problems among Chinese adolescents. Psychiatry Res 111(1), 75-85

Liu X, Uchiyama M, Okawa M, Kurita H (2000a): Prevalence and correlates of self-reported sleep problems among Chinese adolescents. Sleep 23(1), 27-34

Liu X, Sun Z, Uchiyama M, Shibui K, Kim K, Okawa M (2000b): Prevalence and correlates of sleep problems in Chinese schoolchildren. Sleep 23(8), 1053-1062

Lumeng JC, Somashekar D, Appugliese D, Kaciroti N, Corwyn RF, Bradley RH (2007): Shorter sleep duration is associated with increased risk for being overweight at ages 9 to 12 years. Pediatrics $\underline{120}(5), 1020-1029$

McCall WV (2001): A psychiatric perspective on insomnia. J Clin Psychiatry 62 Suppl 10, 27-32

McLaughlin Crabtree V, Beal Korhonen J, Montgomery-Downs HE, Faye Jones V, O'Brien LM, Gozal D (2005): Cultural influences on the bedtime behaviors of young children. Sleep Med $\underline{6}(4), 319-324$

McPherson M, Arango P, Fox H, Lauver C, McManus M, Newacheck PW, Perrin JM, Shonkoff JP, Strickland B (1998): A new definition of children with special health care needs. Pediatrics $\underline{102}(1 \mathrm{Pt} 1), 137-140$

Meerlo P, Sgoifo A, Suchecki D (2008): Restricted and disrupted sleep: effects on autonomic function, neuroendocrine stress systems and stress responsivity. Sleep Med Rev 12(3), 197-210

Mesquita G, Reimao R (2007): Nightly use of computer by adolescents: its effect on quality of sleep. Arq Neuropsiquiatr $\underline{65}(2 \mathrm{~B}), 428-432$

Morin CM, Stone J, Trinkle D, Mercer J, Remsberg S (1993): Dysfunctional beliefs and attitudes about sleep among older adults with and without insomnia complaints. Psychol Aging $\underline{8}(3), 463-467$

Morin CM, Bootzin RR, Buysse DJ, Edinger JD, Espie CA, Lichstein KL (2006): Psychological and behavioral treatment of insomnia:update of the recent evidence (1998-2004). Sleep 29(11), 1398-1414 
Morrison DN, McGee R, Stanton WR (1992): Sleep problems in adolescence. J Am Acad Child Adolesc Psychiatry 31(1), 94-99

National Institutes of Health (NIH): NIH State-of-the-Science Conference Statement on Manifestatons and Management of Chronic Insomnia in Adults. NIH Consens Sci Statements 22 1-30; National Institutes of Health, Kensington, MD 2005

National Sleep Foundation (NSF): 2006 Sleep in America Poll. National Sleep Foundation, Washington, DC, 2006. Available at: http://sleepfoundation.org/media-center/pressrelease/sleep-america-poll-summary-findings; accessed March 19, 2013

Nixon GM, Thompson JM, Han DY, Becroft DM, Clark PM, Robinson E, Waldie KE, Wild CJ, Black PN, Mitchell EA (2008): Short sleep duration in middle childhood: risk factors and consequences. Sleep $\underline{31}(1), 71-78$

North AC, Hargreaves DJ, O'Neill SA (2000): The importance of music to adolescents. Br J Educ Psychol 70 ( Pt 2), 255-272

Ohannessian CM (2009): Media Use and Adolescent Psychological Adjustment: An Examination of Gender Differences. J Child Fam Stud 18(5), 582-593

Ohayon MM (2002): Epidemiology of insomnia: what we know and what we still need to learn. Sleep Med Rev $\underline{6}(2), 97-111$

Ohayon MM, Zulley J (2001): Correlates of global sleep dissatisfaction in the German population. Sleep 24(7), 780-787

Ohayon MM, Roberts RE (2001): Comparability of sleep disorders diagnoses using DSM-IV and ICSD classifications with adolescents. Sleep 24(8), 920-925

Ohayon MM, Guilleminault C, Zulley J, Palombini L, Raab H (1999): Validation of the sleep-EVAL system against clinical assessments of sleep disorders and polysomnographic data. Sleep 22(7), 925-930

Ohayon MM, Roberts RE, Zulley J, Smirne S, Priest RG (2000): Prevalence and patterns of problematic sleep among older adolescents. J Am Acad Child Adolesc Psychiatry 39(12), 1549-1556

Olds T, Ridley K, Dollman J (2006): Screenieboppers and extreme screenies: the place of screen time in the time budgets of 10-13 year-old Australian children. Aust N Z J Public Health $\underline{30}(2), 137-142$

Ortega FB, Chillon P, Ruiz JR, Delgado M, Albers U, Alvarez-Granda JL, Marcos A, Moreno LA, Castillo MJ (2010): Sleep patterns in Spanish adolescents: associations with TV watching and leisure-time physical activity. Eur J Appl Physiol 110(3), 563-573

Paavonen EJ, Solantaus T, Almqvist F, Aronen ET (2003): Four-year follow-up study of sleep and psychiatric symptoms in preadolescents: relationship of persistent and temporary sleep problems to psychiatric symptoms. J Dev Behav Pediatr 24(5), 307-314

Patten CA, Choi WS, Gillin JC, Pierce JP (2000): Depressive symptoms and cigarette smoking predict development and persistence of sleep problems in US adolescents. Pediatrics $\underline{106}(2)$, E23

Perlis ML, Giles DE, Mendelson WB, Bootzin RR, Wyatt JK (1997): Psychophysiological insomnia: the behavioural model and a neurocognitive perspective. J Sleep Res $\underline{6}(3)$, 179-188

Punamaki RL, Wallenius M, Nygard CH, Saarni L, Rimpela A (2007): Use of information and communication technology (ICT) and perceived health in adolescence: the role of sleeping habits and waking-time tiredness. J Adolesc $\underline{30}(4), 569-585$

Qidwai W, Ishaque S, Shah S, Rahim M (2010): Adolescent lifestyle and behaviour: a survey from a developing country. PLoS One $\underline{5}(9)$, e12914

Rhoades KA, Leve LD, Harold GT, Mannering AM, Neiderhiser JM, Shaw DS, Natsuaki MN, Reiss D (2012): Marital hostility and child sleep problems: direct and indirect associations via hostile parenting. J Fam Psychol 26(4), 488-498 
Rideout V, Foehr UG, Roberts D (2010). Generation M. Media in the Lives of 8-18 YearOlds. Henry J. Kaiser Family Foundation. Menlo Park, CA, Henry J. Kaiser Family Foundation. Available at: http://kff.org/other/generation-m-media-in-the-lives-of/; accessed April 3, 2014

Riemann D, Perlis ML (2009): The treatments of chronic insomnia: a review of benzodiazepine receptor agonists and psychological and behavioral therapies. Sleep Med Rev 13(3), 205-214

Riemann D, Spiegelhalder K, Feige B, Voderholzer U, Berger M, Perlis M, Nissen C (2010): The hyperarousal model of insomnia: a review of the concept and its evidence. Sleep Med Rev 14(1), 19-31

Riemann D, Baglioni C, Feige B, Spiegelhalder K (2014): [Insomnia--state of the science]. Nervenarzt $\underline{85}(1), 43-49$

Roane BM, Taylor DJ (2008): Adolescent insomnia as a risk factor for early adult depression and substance abuse. Sleep 31(10), 1351-1356

Roberts DF, Christensen PG: Popular music in childhood and adolescence; in: Handbook of Children and the Media Edited by; Sage Publications, Thousand Oaks, CA 2001, 395410

Roberts RE, Roberts CR, Chen IG (2002): Impact of insomnia on future functioning of adolescents. J Psychosom Res 53(1), 561-569

Roberts RE, Lee ES, Hemandez M, Solari AC (2004): Symptoms of insomnia among adolescents in the lower Rio Grande Valley of Texas. Sleep 27(4), 751-760

Roberts RE, Roberts CR, Chan W (2006): Ethnic differences in symptoms of insomnia among adolescents. Sleep 29(3), 359-365

Roberts RE, Roberts CR, Duong HT (2008a): Chronic insomnia and its negative consequences for health and functioning of adolescents: a 12-month prospective study. J Adolesc Health 42(3), 294-302

Roberts RE, Roberts CR, Chan W (2008b): Persistence and change in symptoms of insomnia among adolescents. Sleep 31(2), 177-184

Rodenbeck A, Huether G, Ruther E, Hajak G (2002): Interactions between evening and nocturnal cortisol secretion and sleep parameters in patients with severe chronic primary insomnia. Neurosci Lett 324(2), 159-163

Roe K (2000): Adolescents' media use: a European view. J Adolesc Health 27(2 Suppl), 1521

Saarenpää-Heikkilä O, Rintahaka P, Laippala PJ, Koivikko MJ (2000): Subjective Daytime Sleepiness and Related Predictors in Finnish Schoolchildren. Sleep and Hypnosis 2(4), 139-146

Sargent JD, Wills TA, Stoolmiller M, Gibson J, Gibbons FX (2006): Alcohol use in motion pictures and its relation with early-onset teen drinking. J Stud Alcohol 67(1), 54-65

Shochat T, Flint-Bretler O, Tzischinsky O (2010): Sleep patterns, electronic media exposure and daytime sleep-related behaviours among Israeli adolescents. Acta Paediatr 99(9), $1396-1400$

Shur-Fen Gau S (2006): Prevalence of sleep problems and their association with inattention/hyperactivity among children aged 6-15 in Taiwan. J Sleep Res 15(4), 403414

Singer MI, Slovak K, Frierson T, York P (1998): Viewing preferences, symptoms of psychological trauma, and violent behaviors among children who watch television. $\mathrm{J}$ Am Acad Child Adolesc Psychiatry 37(10), 1041-1048

Soderqvist F, Carlberg M, Hardell L (2008): Use of wireless telephones and self-reported health symptoms: a population-based study among Swedish adolescents aged 15-19 years. Environ Health $\underline{7}, 18$ 
Sofi F, Cesari F, Casini A, Macchi C, Abbate R, Gensini GF (2014): Insomnia and risk of cardiovascular disease: a meta-analysis. Eur J Prev Cardiol 21(1), 57-64

Spielman AJ, Saskin P, Thorpy MJ (1987a): Treatment of chronic insomnia by restriction of time in bed. Sleep 10(1), 45-56

Spielman AJ, Caruso LS, Glovinsky PB (1987b): A behavioral perspective on insomnia treatment. Psychiatr Clin North Am 10(4), 541-553

Strasburger VC, Jordan AB, Donnerstein E (2010): Health effects of media on children and adolescents. Pediatrics $\underline{125}(4), 756-767$

Taylor DJ, Lichstein KL, Durrence HH (2003): Insomnia as a health risk factor. Behav Sleep Med 1(4), 227-247

Taylor DJ, Mallory LJ, Lichstein KL, Durrence HH, Riedel BW, Bush AJ (2007): Comorbidity of chronic insomnia with medical problems. Sleep 30(2), 213-218

Thorleifsdottir B, Bjornsson JK, Benediktsdottir B, Gislason T, Kristbjarnarson H (2002): Sleep and sleep habits from childhood to young adulthood over a 10 -year period. J Psychosom Res 53(1), 529-537

Took KJ, Weiss DS (1994): The relationship between heavy metal and rap music and adolescent turmoil: real or artifact? Adolescence 29(115), 613-621

Tynjala J, Kannas L, Valimaa R (1993): How young Europeans sleep. Health Educ Res $\underline{8}(1)$, 69-80

Van den Bulck J (2003): Text messaging as a cause of sleep interruption in adolescents, evidence from a cross-sectional study. J Sleep Res 12(3), 263

Van den Bulck J (2004): Television viewing, computer game playing, and Internet use and self-reported time to bed and time out of bed in secondary-school children. Sleep 27(1), 101-104

Van den Bulck J (2007): Adolescent use of mobile phones for calling and for sending text messages after lights out: results from a prospective cohort study with a one-year follow-up. Sleep 30(9), 1220-1223

Vignau J, Bailly D, Duhamel A, Vervaecke P, Beuscart R, Collinet C (1997): Epidemiologic study of sleep quality and troubles in French secondary school adolescents. J Adolesc Health 21(5), 343-350

Vioque J, Torres A, Quiles J (2000): Time spent watching television, sleep duration and obesity in adults living in Valencia, Spain. Int J Obes Relat Metab Disord 24(12), 1683-1688

Wang X, Perry AC (2006): Metabolic and physiologic responses to video game play in 7- to 10-year-old boys. Arch Pediatr Adolesc Med 160(4), 411-415

Weaver E, Gradisar M, Dohnt H, Lovato N, Douglas P (2010): The effect of presleep videogame playing on adolescent sleep. J Clin Sleep Med $\underline{6}(2), 184-189$

Wells A, Hakanen EA (1991): The emotional use of popular music by adolescents. Journal Q $\underline{68}(3), 445-454$

Winkler J, Stolzenberg H (1999): [Social class index in the Federal Health Survey]. Gesundheitswesen 61 Spec No, S178-183

Wood AW, Loughran SP, Stough C (2006): Does evening exposure to mobile phone radiation affect subsequent melatonin production? Int J Radiat Biol 82(2), 69-76

World Health Organisation (WHO): International Statistical Classification of Diseases and Related Health Problems: ICD-10; Publisher: World Health Organisation, Geneva, Switzerland 2010

Yen CF, Ko CH, Yen JY, Cheng CP (2008): The multidimensional correlates associated with short nocturnal sleep duration and subjective insomnia among Taiwanese adolescents. Sleep 31(11), 1515-1525

Zhang B, Wing YK (2006): Sex differences in insomnia: a meta-analysis. Sleep 29(1), 85-93 
Zimmermann FJ (2008). Children's Media Use and Sleep Problems: Issues and Unanswered Questions. Henry J. Kaiser Family Foundation. Menlo Park, CA, Henry J. Kaiser Family Foundation. Available at: http://kff.org/other/issue-brief/childrens-media-useand-sleep-problems-issues/; accessed April 9, 2014 


\section{Veröffentlichungen}

Teile dieser Arbeit wurden in Form eines Vortrages und hiermit assoziiertem Abstract vorab veröffentlicht.

Vortrag: Lange K, Cohrs S, Skarupke C, Kunz D, Szagun B, Schlack R: Electronic Media Use and Insomnia Complaints in German Adolescents (11-17 years).

Präsentiert am 8. Dezember 2012 auf der Jahrestagung der Deutschen Gesellschaft für Schlafmedizin (DGSM) in Berlin. Abstract verfügbar in: Somnologie 16 (Abstracts der 20. Jahrestagung der DGSM, 6.-8. Dezember 2012, Berlin), Sonderheft 1, 34-35 


\section{Danksagung}

Ich danke herzlich Herrn Priv.-Doz. Dr. med. Stefan Cohrs für die Bereitstellung des Themas für diese Arbeit. Sein Enthusiasmus für die wissenschaftliche Arbeit zum Thema Schlaf und seine Unterstützung und Offenheit für Fragen und Anregungen haben diese Arbeit in dieser vorliegenden Form erst möglich gemacht. Besonderen Dank möchte ich auch Herrn Robert Schlack vom Robert Koch-Institut aussprechen, denn ohne seine Unterstützung hätte diese Arbeitsgruppe die Spannbreite des KiGGS Datensatzes nicht erfassen und für diese Studie in dieser hohen Qualität einsetzen können. Nicht zuletzt möchte ich auch Herrn Dr. med. Christian Skarupke für seine Unterstützung und Motivation während der Entwicklung dieser Arbeit herzlich danken. 


\section{Lebenslauf}

Anna Karoline Stephens Lange wurde am 10.10.1985 in Boston, Massachusetts, USA als erste Tochter eines deutschen Vaters und einer amerikanischen Mutter geboren. Bis zu ihren fünften Lebensjahr lebte sie in den USA und die Familie zog dann nach Bremen, Deutschland, wo sie ihre schulische Ausbildung begann. Von 1995 bis 2004 besuchte sie das Ökumenische Gymnasium zu Bremen und verbrachte während dieser Zeit das elfte Schuljahr an der Loomis Chaffee School in Windsor, Conneticut, USA. Nach dem Abitur im Jahre 2004 belegte sie den Diplomstudiengang der Psychologie an der Universität Göttingen, aber bewarb sich schon nach zwei Semestern für das Medizinstudium. Im Wintersemester 2005 begann sie das Medizinstudium an der Universität Göttingen, wo sie auch im Herbst 2007 das erste Staatsexamen erfolgreich absolvierte. Nachdem sie das Wahlfach Schlafmedizin belegt hatte, begann sie im Jahre 2009 unter der Aufsicht von Priv.-Doz. Dr. med. Stefan Cohrs ihre Promotionsarbeit zum Thema Schlafstörungen im Zusammenhang mit der Nutzung elektronischer Medien im Jugendalter. Im Laufe der klinischen Ausbildung verbrachte sie einen Teil ihrer Famulaturen und ihres Praktischen Jahres mit Begeisterung in den USA und absolvierte dann im Winter 2012 das zweite Staatsexamen Medizin. Im darauf folgenden Jahr bestand sie erfolgreich die Voraussetzungen für die Bewerbung für eine Residency in den USA und seit dem Sommer 2014 ist sie Resident der Inneren Medizin an der Abbott Northwestern Hospital in Minneapolis, Minnesota, USA. 